\title{
Qi-Transformation and the Steam Engine The Incorporation of Western Anatomy and Re-Conceptualisation of the Body in Nineteenth- Century Chinese Medicine
}

\author{
Sean Hsiang-lin Lei \\ Institute of Modern History, Academia Sinica, Taiwan and \\ Institute of Science, Technology and Society, Yangming University
}

\begin{abstract}
Tang Zonghai (1851-1908), the widely acclaimed proponent of medical eclecticism in the late Qing period, invented the famous formula: 'Western medicine is good at anatomy; Chinese medicine is good at $q i$-transformation.' While it is well-known that Tang coined the concept of qibua 氣化 (qi-transformation) and thereby created a long-lasting dichotomy between Chinese and Western medicine, it is little known that Tang's conception of $q$ i-transformation was built upon, and therefore heavily influenced by, a newly-imported technology from the West, namely the steam engine.

Based on this surprising discovery, this article intends to make three interrelated arguments. First, Tang Zonghai drew on the newly invented model of the steam engine and the related concept of steam to create a new understanding of $q i$-transformation in the human body. Second, this new understanding of $q i$ enabled him to reform Chinese medicine by incorporating the new knowledge and visual illustrations of Western anatomy, most notably the illustration of the peritoneum from Gray's Anatomy and the existence of the ureters. And third, in the dual process of developing the new understanding of $q i$-transformation and incorporating Western anatomy into Chinese medical doctrines, Tang radically re-conceptualised and re-visualised the body of Chinese medicine, especially the three interrelated organs of the bladder, the Triple Burner, and the kidney. Instead of creating an invisible and immaterial world of qi-transformation in opposition to the materialism of Western anatomy, Tang made his conception of qi-transformation instrumental for the incorporation of Western anatomy into Chinese medical doctrines. With the help of this new understanding of $q i$ as steam, Tang systematically responded to the criticisms raised by Benjamin Hobson and Wang Qingren, formally starting the difficult and problematic process of (re)-visualising the Chinese medical body.
\end{abstract}

\section{Keywords}

Chinese medicine, Tang Zonghai, qi, modernity, body, bladder, Triple Burner, anatomy, visualisation 


\section{A Puzzle}

Arguably the most fundamental concept in traditional Chinese medicine, $q i$ is a term that is impossible to translate into English but that has entered common English usage. To this day, advocates and practitioners characterise Chinese medicine as being founded on the theory of qihua 氣化, that is, $q$ i-transformation. Inspired by this concept, for instance, Huang Yueting 黃月庭 coined the term qigong 氣功 in 1949 when he was looking for a new name for a set of bodily training exercises that he had developed with some colleagues in the 'Liberated Zone' of Southern Hebei. ${ }^{1}$ As Huang designed the term qigong to associate this set of physical exercises with the four-thousandyear 'tradition' of Chinese medicine, he likely did not realise that the phrase qihua as a way of characterising Chinese medicine had been a recent invention from the late nineteenth century.

The medical concept of qihua was created by Tang Zonghai 唐宗海 (1851-1908), the widely acclaimed founder of the School of Converging Chinese and Western Medicine (Zhongxiyi huitong xuepai 中西醫匯通學派). ${ }^{2}$ Lacking any family background in medicine, he devoted the first half of his life to preparing for the civil service examination. Nevertheless, unlike many other scholar physicians (ruyi 儒醫) who turned to medicine only later in their careers, often after repeatedly failing the civil service examination, Tang succeeded at the relatively young age of 38 in achieving the prestigious rank of 'presented scholar' (jinshi 進士). ${ }^{3}$ Having attained the status of a 'presented scholar,' he was a rare exception in that he chose medicine over a lucrative and highly-regarded career as government bureaucrat, which was virtually guaranteed due to the merits of this status. Starting out as a traditional practitioner, he made a name for himself in Sichuan Province as the result of his clinical skills, especially after the publication of a book titled On Blood Disorders (xuezhenglun 血證論) in 1884. After travelling to the Jiangnan area, most notably Shanghai, in the 1880s, he became strongly interested in Western medicine. Finally, in 1892, he published a path-breaking book with the title Essential Meanings of the Medical Canons [Approached] through the Convergence and Assimilation of Chinese and Western [Medicine] (Zhongxi huitong yijing jingyi 中西匯通醫經精義, abbreviated below as Essential Meanings of the Medical Canons), the key text discussed in detail in this article. A powerful testimony to Tang Zonghai's long-lasting influence comes from Zhang Xichun 張錫純 (1860-1933), who came to be known as the master of converging Chinese

\footnotetext{
${ }^{1}$ For a history of the creation of qigong, see Palmer 2007.

2 See, for example, Xie 1935, p. 56.

${ }^{3}$ For Tang's biography, see Pi 2006b, pp. 21-36.
} 
and Western medicine during the Republican period. Passionately recollecting in the 1930s the enlightening experience that he had gained from reading the Essential Meanings of the Medical Canons, he credited Tang Zonghai's work as the departure point for his own seven-volume project of integrating the two styles of medicine. ${ }^{4}$

It was in the Essential Meanings of the Medical Canons that Tang Zonghai first presented the following famous formula: Western medicine is good at visible configuration (xingji 形跡); Chinese medicine is good at qibua (qi-transformation). ${ }^{5}$ In other words, it was during Tang's comparison of Chinese medicine with Western anatomy in the late nineteenth century that Chinese medicine first acquired the characterisation that has persisted to this day, that is, the notion that Chinese medicine is centred on qi-transformation. Despite this continuity of the term $q i$-transformation from Tang's time until today, its implied relationship between two medical traditions has gone through a great reversal. Until the first decade of the twentieth century, most practitioners of Chinese medicine considered the opposition between $q i$-transformation and anatomy as referring to the relative strength of two medical traditions-they were simply good at two different tasks. As I have documented elsewhere, ${ }^{6}$ however, practitioners of Chinese medicine such as Yun Tieqiao and Yu Jianquan transformed this comparison of relative strength into a binary dichotomy between two incommensurable conceptions of the human body when they were forced to defend Chinese medicine against its critics in the 1920s. By interpreting qi-transformation as a concept that was concerned exclusively with the invisible and immaterial processes of the human body, they argued that the body of Chinese medicine was beyond the visible and material realm of Western anatomy, and therefore immune to any criticism from modern science. In light of this history, we must confront the following puzzle: if the notion of $q$ - -transformation that had been formulated by Tang Zonghai was the incommensurable opposite of modern science, how did it come to serve as the tool for converging Chinese medicine and Western anatomy in the late nineteenth century?

The key to this puzzle lies in the little-noticed fact that Tang prided himself on having invented a new conception of $q i$ for this purpose. In a key paragraph in the Essential Meanings of Medical Canons, he reasoned:

From the Tang dynasty on, no one has understood the term qihua. Therefore, I would like to elaborate here. As fire encounters water, it transforms it into qi. If

${ }^{4}$ Quoted from Wang 1999, p. 640.

5 Tang 1987 b, p. 1.

${ }^{6}$ Lei 1999, pp. 164-73. 
you look at the way in which Westerners use fire to boil water and collect steam [referred to in Chinese as qing $q i$ 輕氣, 'light $q i$ ], you find evidence that when fire encounters water, it transforms it into $q i^{7}$

This paragraph includes several noteworthy points. First of all, he made clear that he was reinvigorating a forgotten tradition of $q i$-transformation. Second, when he elaborated on the idea of $q i$-transformation, which he presumed to be the very foundation of Chinese medicine, he explicitly drew on a phenomenon that was the key characteristic of a so-called 'Western method' (xifa 西法). The question then becomes: What was it that was particularly novel or 'Western' about this method? This question is particularly pertinent since it appeared to involve nothing more than the simple process of using fire to boil water.

The answer to this question is simple yet surprising: Tang Zonghai's conception of $q i$-transformation was indeed novel and 'Western' because what he called the 'Western method' of using fire to boil water referred to the creation of $q i$ within a newly imported technology from the West-the steam engine.

\section{The discovery of steam in China}

At first glance, it is hard to imagine that steam would have been such a novel concept in late Qing China. Boiling water by means of fire is an experience common to people around the globe, especially to the tea-drinking people of East Asia. Both Chinese and Japanese writers have left detailed reports about their observations of the process of boiling water to prepare tea. Nevertheless, the utilization of steam as a source of power is not a universal experience at all. The first recorded practical use of steam is related to the invention of a machine for lifting water, used in the mining industry in late seventeenthand early eighteenth-century England. Since the British at that time did not yet realise the central role played by steam in this process, they called the machine 'fire-engine', emphasising the power of combustion. It was not until the 1760s that James Watt (1736-1819) and his contemporaries began to investigate the possibilities of using steam pressure to generate power. They soon realised that the steam thus created could be collected, channelled, intensified, condensed, and — most importantly_used as a new source of power to substitute for human, animal, and other natural sources that humanity had relied on since the dawn of history. As Watt's steam engine used 75 per cent less coal than the traditional fire engine, his machine thus paved the way for the Industrial Revolution in England. ${ }^{8}$

7 Tang 1987 b, p. 51.

${ }^{8}$ Cardwell 1989, pp. 40-55. 
The use of steam as a source of power was such a radical invention that it took the Chinese of the late Qing period two decades to 'discover' this public knowledge, according to a recent study by Hsien-chun Wang. ${ }^{9}$ After the Chinese army suffered a historic defeat by British steamboats during the Opium War in 1840, a number of Chinese government officials tried to build such a boat on the basis of their observations of the exterior of the British boats. Having noticed that 'when the fire is burning in the furnace, the two wheels turn like a fast mill', they drew a mental connection between the moving wheels and the furnace. Because they were unaware, however, of the power of steam, which was the key intermediate factor, they understandably referred to steamships as 'fire-wheel ships' (buo lun chuan 火輪船). ${ }^{10}$ When Qi Ying 耆英 (1787-1858), the imperial commissioner who signed the historic Treaty of Nanking, boarded the HMS Cornwallis and witnessed its machinery at the end of the Opium War in 1842, he reported to the Emperor that, 'It is rumoured that there are men or oxen driving the gears (of the water cylinder). ${ }^{11}$ Even after having been on board the British steamboat, Qi Ying still failed to recognise the role of steam and therefore ended up speculating falsely about its power source.

It was not until two decades later, after consulting the medical missionary Benjamin Hobson's (1816-73) Treatise of Natural Philosophy (Buowu xinbian 博物新編, 1855), that Xu Shou 徐壽 (1818-84) and Hua Hengfang 華蘅芳 (1833-1902) succeeded in building a model engine. In 1862, they presented their model to Zeng Guofan 曾國藩 (1811-72), the leading Qing military commander and newly-appointed governor-general of Jiangsu, Jiangxi, and Anhui. Describing the operation of this engine in his diary, Zeng Guofan noted: 'The method consists of using fire to make steam and then directing the steam into a cylinder... The bigger the fire, the greater the quantity of steam. ${ }^{12}$ Despite such a primitive and imprecise understanding, the secret of the steam engine that Zeng had finally learned was exactly the 'Western method' that Tang Zonghai explicitly referred to in the quote on qi-transformation cited above- the method of producing steam by means of fire.

Tang must have been familiar with the concepts of the steam engine and of steam. In the ending paragraphs of his Essential Meanings of the Medical Canons, he stated as his most sincere hope that people who specialised in 'mathematics and the steam engine' (qiji 汽機) would in the future pursue

\footnotetext{
9 Wang 2010.

10 Wang 2010, p. 38.

11 Wang 2010, p. 41.

12 Quoted from Wang 2010, p. 48.
} 
this endeavour further to converge Chinese and Western medicine. ${ }^{13}$ While this is the only place where he mentioned the term steam engine in his Essential Meanings, he correctly used the new character that had been invented by Benjamin Hobson in his influential Treatise of Natural Philosophy more than three decades before. To signal the novelty of the concept of steam, Hobson had created the character $q i$ 汽, a combination of the traditional character for $q i$ with the water radical (semantic indicator), to translate the concept of steam into Chinese, defining it as the kind of $q i$ that is created when water is forced by heat to move upward. ${ }^{14}$ In addition, Hobson had coined three related Chinese terms to translate the concepts of the steam engine (qiji 汽機), steam power (qili 汽力), and again steam (zhengqi 蒸汽). In all these terms, the Chinese character for $q i$ 汽 includes the newly-added radical representing water; this form of $q i$ is thus clearly connected to water. ${ }^{15}$

At this point in my argument, it is useful to replicate the illustration of the steam engine that was included in Hobson's Treatise of Natural Philosophy. This is the exact image that Tang Zonghai must have seen himself, since he cited this book in his Essential Meanings. ${ }^{16}$ Although the diagram is still entitled huolunji tu 火輪機圖, literally translated as 'Illustration of the fire-wheel machine', many of its components are referred to with compound terms that included the new character $q i$ 汽. Within the text, moreover, Hobson consistently uses the term qiji instead of 'fire-wheel machine'. In fact, it is highly possible that Hobson was the person who created this neologism to render the novel concept of steam into Chinese; ${ }^{17}$ it was included in his "A Medical Vocabulary in English and Chinese" published in 1858. ${ }^{18}$ Making note

13 Tang 1908, vol. 2, p. 38. Throughout this article, whenever I quote Tang's Essential Meanings of Medical Canons, I am referring to the edition published by Lixing Shuju in 1987 in Taipei. Unfortunately, the Lixing edition does not include the last section of the book, which is the section that includes the key term qiji. Because of this omission of the Lixing edition, here and only here, I am referring to the 1908 edition published in Shanghai. With regards to the illustrations from this book, however, I also used those from the 1908 edition because of their better visual quality. I would like to thank my colleague Chang Che-chia for informing me that Tang in fact did use the term qiji once in this book at a point in my research when I thought that he never had, due to my reliance on the Lixing edition.

${ }^{14}$ Hobson 1855 , p. 38.

15 Another translation of steam is shui zheng qi 水蒸氣 ('water steam $q i$ ), which was borrowed from the Japanese translation of the English term. This term did not become popular until China was defeated in the Sino-Japanese war in 1895 and started sending students to study in Japan.

16 Tang $1987 b$, p. 12.

${ }^{17}$ For a history of the introduction of scientific terms into Chinese, see Lackner et al, 2001. I would like to thank Marta Hanson for asking me the perceptive question about whether this Chinese character was a neologism.

${ }^{18}$ Hobson 1858, p. 73. 


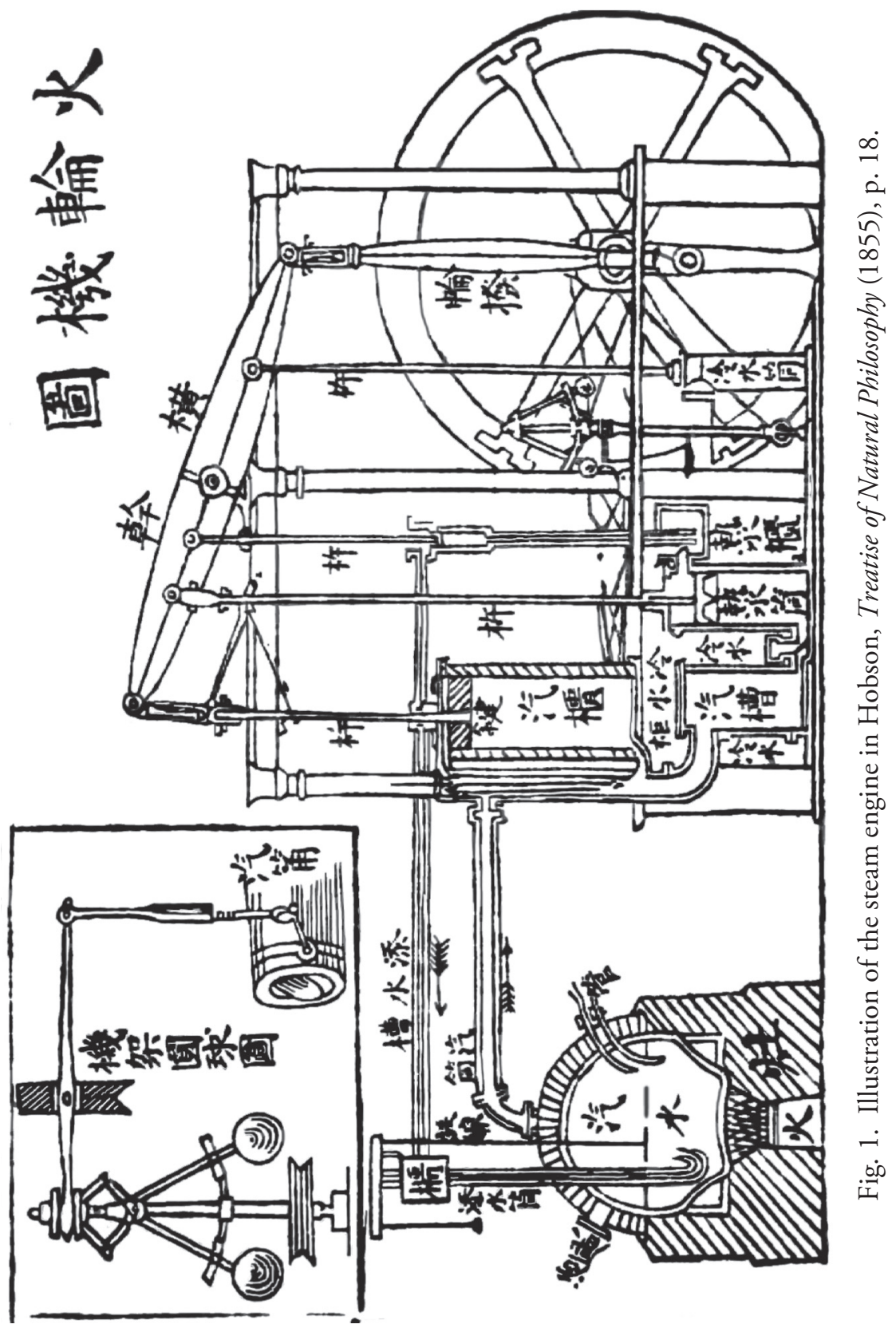


of Hobson's effort, when Xu Shou published an article to explain the name of the steam engine in 1876, he explicitly pointed out that the so-called firewheel ship 'is actually operated with shui $q i$ 水氣 ('water $q i$ ) and therefore should be named 'wheel-ship operated by the steam engine' (qiji 汽機). ${ }^{19}$

For two reasons, readers might doubt my assertion that Tang Zonghai had indeed created his conception of $q i$-transformation on the basis of the steam engine. First, he did not use the term $q i$ 汽 but rather qing $q i$ (輕氣) in the key paragraph quoted in my introduction above. Qing qi literally means 'light $q i$ and was used by Hobson to translate the concept of hydrogen into Chinese. If Tang Zonghai had really meant hydrogen when he used the term qing $q i$, his conception of $q i$-transformation would have nothing to do with steam engines. Secondly, he mentions the term qiji only once in his Essential Meanings, which seems to contradict my argument with its emphasis on the role of the steam engine. In the following sections, I will explain in detail how Tang built this parallel between $q i$-transformation within the human body and the production of steam inside the steam engine. Meanwhile, I would like to offer evidence to show the paramount role that the steam engine occupied in Tang's mind. Several years after the publication of Essential Meanings, he composed a whole book, entitled A Generalised Account of Medicine and the Classic of Changes (Yiyi tongshuo 醫易通說), to argue that the principles of 'steam engine and chemistry', while allegedly imported from the West and previously unheard of in China, had already been included in the Classic of Changes (yijing 易經). ${ }^{20}$ Just like many other reform-minded intellectuals of the late Qing period such as Zheng Guanying 鄭觀應 (1842-1922), the 'presented scholar' Tang Zonghai saw the steam engine as the embodiment of Western power and the crucial challenge facing Chinese civilization. But unlike his literary colleagues, he was unique in translating this challenge into the technical field of medicine and, most importantly, into a tool for converging Chinese and Western medicine.

\section{The bladder as the origin of $q i$-transformation}

It was in the discussion of the urinary bladder, the most marginal of the visceral organs in Chinese medical theory, which Tang Zonghai elaborated on his conception of qi-transformation and the so-called Western method of producing steam. Following the above-quoted statement comparing $q i$ transformation to the transformation of water into steam by means of fire, he

19 Xu 1876, p. 6.

20 Tang 1992, pp. 151-2. 
pushed the metaphor further with the following question: How do fire and water encounter each other inside the human body?21

This question reveals the power of this metaphor in framing his way of thinking. The metaphor of the steam-making machine leads the reader to think about (a) the channelled movement of fire and water, (b) the place where they interact, and (c) the way in which qi or steam is created, circulated, and finally condensed. With the help of this metaphor, Tang urged people to pay close attention to the bladder (pangguang 膀胱) as the place where 'fire and water encounter each other' inside the human body.

Tang was keenly aware that he was proposing a revolutionary view of the role of the bladder. Interpreting a passage from the Inner Canon (neijing 內經) about the bladder, he commented:

People only know that the bladder governs urination. They do not realise that once water enters the bladder, it is transformed into $q i$ and moves upward, where it is further transformed into nourishing fluids (jinye 津液), while the residual substance, which moves downward, is transformed into urine. The substance that the Inner Canon described as 'able to exit from here [i.e., the bladder] as the result of qi transformation' (qihua ze neng chu yan 氣化則能出焉) refers precisely to these nourishing fluids but not to urine. ${ }^{22}$

Tang Zonghai's radical reinterpretation of the functions of the bladder explains why he dared to claim that no one had understood the meaning of $q i$-transformation since the Tang dynasty (618-906). ${ }^{23}$ The unnamed target of this statement is of course Wang Bing 王冰 (710-804), whose annotated compilation of the Inner Canon has been widely respected as the authoritative edition ever since its publication in the eighth century. According to Wang Bing's commentary,

[The bladder] stores the nourishing fluids. With the assistance of $q i$, which is coming from the 'sea of $q i$ ' ( $q$ ihai 氣海), urine pours out; when the qi coming from the 'sea of $q i$ fails to reach the bladder, [the urine] will stay contained [therein]. Therefore the text [of the Inner Canon] says 'able to exit from here as the result of qi-transformation' (qihua ze neng chu yan 氣化則能出焉). ${ }^{24}$

According to this explanation, what poured out from the bladder was urine. Moreover, far from representing the physiology of the whole body, qi-transformation in the bladder was merely the mechanism that people relied on to discharge their liquid waste. Because this is the only place where the Inner Canon applied the

${ }^{21}$ Tang 1987 b, p. 51.

22 Ibid.

${ }^{23}$ Throughout history, other scholars developed interpretations similar to Tang's, but without involving the metaphor of the steam engine. For other views on the bladder by Chinese medical authors, see Wang and Zhang 2010.

${ }^{24}$ Wang 1986, pp. 254-39. 
term qihua to discuss the human body, Tang Zonghai criticised Wang Bing's interpretation of this short paragraph as effectively having obscured the true meaning of qi-transformation for centuries. As the result, 'people only know that the bladder governs urination', he bitterly complained..$^{25}$

Instead of being a peripheral organ in charge of urination, the bladder became for Tang the central organ where qi originated, because it was the meeting place of water and fire. By itself, the bladder was unable to transform water into $q i$; it required the assistance of something else, which provided the necessary fire. And that assistance came from a membranous chamber attached to the back of the bladder, called the 'cinnabar field' (dantian 丹田), or 'sea of $q i$ ' (qihai 氣海) in the male body, and the womb (zigong 子宮) or 'sea of blood' (xuehai 血海) in the female body. ${ }^{26}$ Tang was very confident of his interpretation; in quite a few places, he used pictures, with inscriptions, to depict this close physical relationship between the bladder and the "cinnabar field' (For example, see figure 1). ${ }^{27}$

To articulate the metaphor of steam making inside the human body, he pointed out elsewhere that '[the function of] the bladder is like storing water in a cauldron; [the function of] the cinnabar field is like feeding firewood into a stove. ${ }^{28} \mathrm{He}$ explained the process that took place inside the human body as similar to the way in which a burner and a boiler cooperate to create steam in man-made machines:

The inhaled $q i$, regarded as yang fire, combines with fire from the heart and sinks all the way down into the sea of $q i$. As the sea of $q i$ is adjacent to and closely connected to the bladder, fire steams (zhengdong 蒸動) the water that is stored in the bladder and transforms it into qi. There is no difference between this process and the Western method of using fire to boil water and collect $q i{ }^{29}$

In both the beginning and end of the paragraph that this quotation is excerpted from, he referred to the 'Western method' when he explained his conception of qi-transformation. Three novel elements appear to have been closely connected in his mind: the conception of $q i$-transformation, the central status of the bladder, and the 'Western method' of producing steam.

In this context, modern readers might stumble over the concept of the 'cinnabar field' as the male counterpart of the female womb, since no such entity exists in modern anatomy. In fact, as I will explain in detail in the next section, Tang Zonghai's illustration of the bladder was copied from a book

25 Tang $1987 b$, p. 51

${ }^{26}$ Tang $1987 b$, p. 93.

27 Tang $1987 b$, pp. 43, 45, 93, and 97, but especially p. 43.

28 Tang $1987 b$, p. 43.

29 Tang 1987b, p. 51. 


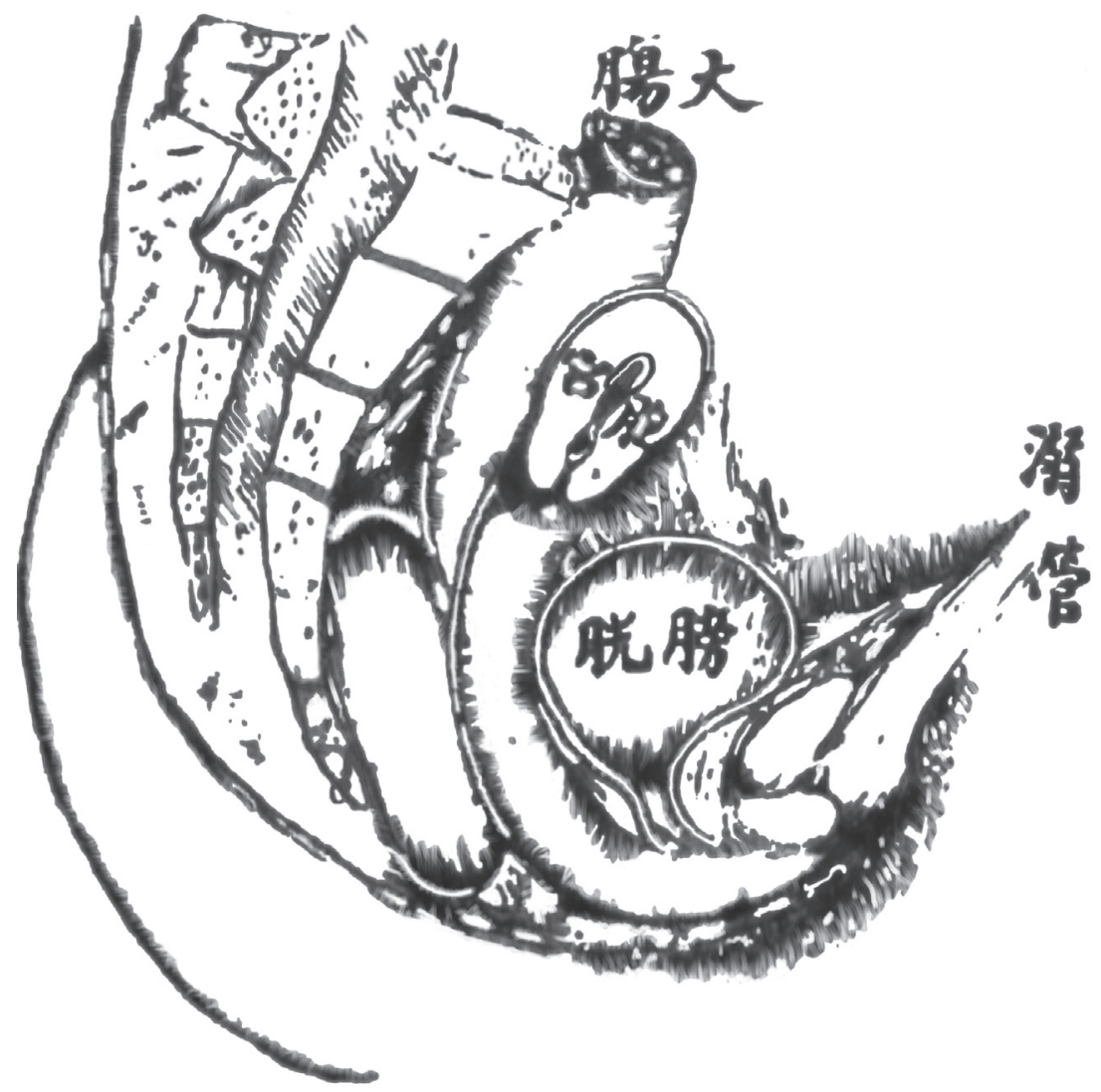

Fig. 2. Illustration of the bladder in Tang Zonghai, Essential Meanings of the Medical Canons (1908), vol. 1, p. 24.

of Western anatomy, with the original title 'section of female pelvis'. When Tang adopted this image of the distinctly female body to represent both the male and the female body, this must have been a deliberate decision on his part. As Yi-li Wu has pointed out, while practitioners of Chinese medicine recognised the womb as a distinctive feature of the female body, '[b] eginning in the seventeenth century, however, learned doctrines explicitly subordinated this female womb to a universalistic model of human reproductive function: both men and women had wombs, it was just that the female womb produced babies. ${ }^{30}$ Tang Zonghai had so much confidence in this doctrine, especially in

30 Wu 2010a, p. 97. 
the existence of the cinnabar field as the male counterpart of the womb, that he highlighted this discrepancy between Chinese medical theory and Western anatomy as follows:

While the Western art of dissection is very refined, practitioners of Western medicine see the location behind the bladder and in front of the large intestine as occupied by the womb (baogong 胞宮) in women only but not by a womb... in men. ${ }^{31}$

After explaining why the male counterpart of the female womb was so easy to miss, he further suggested:

[The cinnabar field] is also called the sea of $q i$. When qi enters [the cinnabar field], one senses swelling in the position below the navel. This is proof [that $q i$ is stored there in cinnabar field]..$^{32}$

It is remarkable that Tang made use of Western illustrations to support a revolutionary conception of $q i$-transformation (see figure 2 ) on the one hand, but at the same time did not hesitate to suggest that Western anatomy had failed to recognise a number of anatomical entities about which practitioners of Chinese medicine possessed valuable knowledge. We may thus say in conclusion that he did not oppose anatomy in principle, partially because he believed that practitioners of Western medicine did not possess a monopoly on anatomical knowledge.

\section{Depicting the Triple Burner}

Since the bladder, in Tang Zonghai's vision of the human body, is the place where fire and water meet, we are naturally led to wonder where these two substances originate. Concerning the movement of fire within the body, Tang's view is relatively conventional. It was in the process of explaining the source of water that he claimed to have resolved the thousand-year-old controversy within Chinese medicine regarding the nature of the so-called 'Triple Burner' (sanjiao 三焦), namely whether it should be thought of as a material entity or a conceptual construct. ${ }^{33}$ Against the backdrop of these long-lasting and complicated debates, ${ }^{34}$ it is remarkable how heavily Tang Zonghai's arguments drew on illustrations from Western anatomy.

\footnotetext{
31 Wu $2010 a$, p. 90.

32 Ibid.

33 According to Nathan Sivin, the Triple Burner was seen as 'immaterial, a single organ, three organs, a membrane lining the body cavity or an abstract division of the yin visceral systems into three areas of functions'. Sivin 1987, pp. 124-5.

${ }_{34} \mathrm{Pi}$ Guoli's recent study meticulously documents the evolution of this controversy and the contesting viewpoints. Pi $2006 a$.
} 


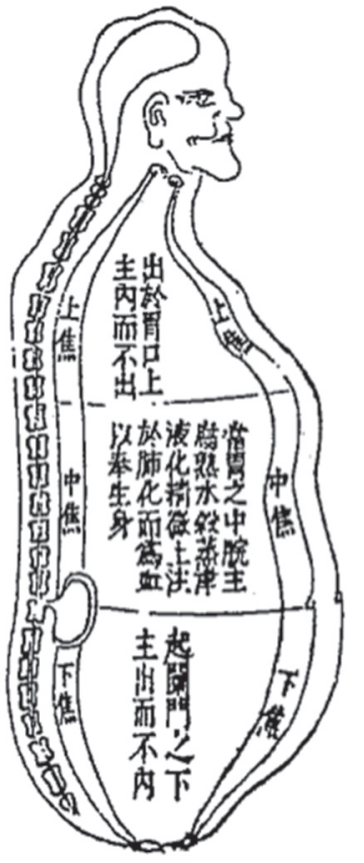

Fig. 3. Illustration of the Triple Burner in Zhang Jiebin, Illustrated Supplement to 'The Inner Canon Explicated by Topic' (1624).

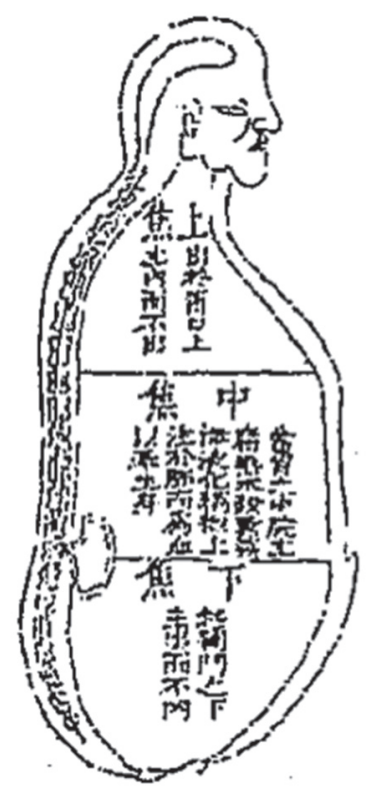

Fig. 4. Illustration of the Triple Burner in Wang Honghan, The Origin of Medicine (1692).

In order to contextualise the visual aspect of his position, I would like to introduce the debate by way of two drawings, associated with two contending parties. At first glance, the two illustrations of the Triple Burner (figures 3 and figure 4 above) look rather similar; even the texts inscribed in the body are identical quotations from the Inner Canon. Despite these similarities, however, they actually represent two contesting views about the nature of the Triple Burner. Included in the Illustrated Supplement to the Inner Canon Explicated by Topic (Leijing tuyi 類經圖翼), which was authored by Zhang Jiebin 張 介賓 in 1624, figure 3 was meant to represent the Triple Burner as a visible material reality. By contrast, figure 4, found in The Origin of Medical Learning (Yixue yuanshi 醫學原始) authored by Wang Honghan 王宏翰 in 1692, was intended to support the view that the Triple Burner was merely a conceptual construct. Since these two illustrations look so similar-both include the same inscriptions and divide the body into three sections-we might wonder how they can be representing such opposing views of the Triple Burner. 
If we look closely, though, we notice that in Zhang Jiebin's illustration (figure 3), the labels '上焦' (shangjiao, i.e., Upper Burner), '中焦' (zhongjiao, i.e., Middle Burner), and '下焦' (xiajiao, i.e., Lower Burner) are placed between a pair of (roughly) parallel lines that separate them from the main text of the three explanations in the centre of the body. By graphically creating an envelope with these parallel lines, Zhang Jiebin's illustration thus suggested that the Triple Burner was a material entity of a certain thickness.

The first Chinese attempt to resolve this debate through 'anatomical examination' was made by none other than the famous late Qing critic of Chinese medicine, Wang Qingren 王清任 (1768-1831). The resulting book, entitled Correcting the Errors of Medicine (Yilin gaicuo 醫林改錯) and published in 1830 , represents the culmination of the attacks on Chinese medicine for its purported ignorance of human anatomy. ${ }^{35}$ Having examined corpses found in public graveyards, Wang Qingren concluded that 'the configurations of the visceral organs depicted in the medical canons do not match those of the real human body at all. ${ }^{36}$ What concerned Wang Qingren most was the nature of the Triple Burner. When he first examined the corpses in person in 1797, he discovered that the human body did not include any anatomical structure equivalent to the Triple Burner. The only structure that he could find in these dead bodies was the diaphragm (gemo 隔膜), which was 'as thin as a piece of paper but of crucial importance. ${ }^{37}$ Because the diaphragms had been damaged in the corpses he investigated, he was not sure "whether the diaphragm was below or above the heart. ${ }^{38}$ After another three attempts to see the diaphragm in human bodies (in 1799, 1820, and 1828), and a consultation with a Qing official who had observed many cadavers of executed criminals, Wang Qingren concluded his four-decade-long investigation by asserting that 'only the lungs and heart are located above the diaphragm. ${ }^{39}$ To visually demonstrate the contrast between the conventional view of Chinese medicine and his personal findings about the Triple Burner, Wang Qingren included in his book the following two illustrations (figures 5 and 6) and congratulated himself for exposing the absurdity of the idea of the Triple Burner.

If we map this pair of illustrations on to the opposing views represented by Zhang Jiebin (figure 3) and Wang Honghan (figure 4), Wang Qingren, on the one hand, rejected the possibility that the Triple Burner was a conceptual

\footnotetext{
35 Andrews 1991 and 2007; Wang D.-H. 1995.

36 Wang Q.-R. 1995, p. 4.

37 Ibid.

38 Ibid.

39 Wang Q.-R. 1995, p. 7.
} 


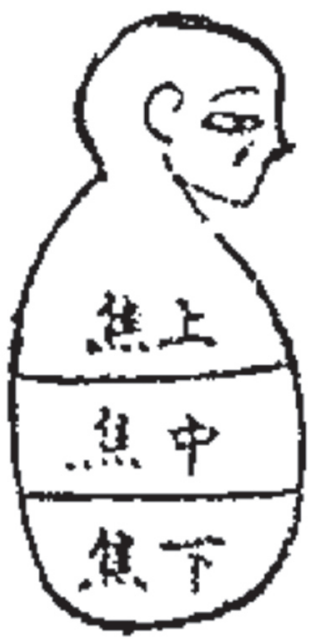

Fig. 5. Illustration of the Triple Fig. 6. Illustration of the diaphragm Burner in Correcting the Errors of in Correcting the Errors of Medicine, Medicine, p. 6, based on conventional p. 7, based on Wang Qingren's own wisdom.

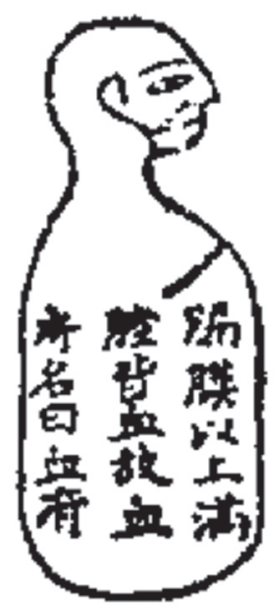

observations.

construct. On the other hand, he also refuted the idea that the Triple Burner included any physical structure other than the diaphragm.

It was in response to this long-lasting controversy over the nature of the Triple Burner, especially to Wang Qingren's recent refutation of its existence, that Tang Zonghai began to construct a new conception of the Triple Burner, making it an essential part of the machinery of the human body, which was conceptualised in its functioning like the modern steam engine. He argued accordingly:

Ever since the Tang dynasty, people have failed to realise what the Triple Burner is. According to Western medicine, as soon as [water] enters the stomach whose wall is covered with blood capillaries, water is sucked out into the diaphragm (gemo 隔膜) and sent through an 'interconnected net of oily membranes' (lianwang youmo 連網油膜) farther down into the bladder. ${ }^{40}$

It was no accident that he claimed that the true meaning of the Triple Burner, just like that of $q$ i-transformation, had become obscured since the Tang dynasty. To say that these two issues were interconnected in his view of the human body is an understatement; rather, it was his novel conception of $q i$ as steam that determined his take on the much-debated identity of the Triple

40 Tang $1987 b$, p. 50. 
Burner. According to Tang, qi/steam was created in the bladder because it was the place where water and fire crossed paths. The problem is that, as Tang claimed, Chinese medicine had for centuries wrongly identified the channel through which water was transmitted into the bladder-a crucial mistake that I will discuss in detail in the next section. Fortunately, Western medicine had knowledge about what transmitted water from the stomach into the bladder; it was an 'interconnected net of oily membranes' (lianwang youmo 連網油膜, the Chinese translation for 'peritoneum'). ${ }^{41}$ Tang Zonghai presented this missing piece, that is, the presence of this 'net of membranes', as the ideal candidate for fulfilling the role of supplying water to the bladder, a role that the Inner Canon had long attributed to the Triple Burner.

Based on this understanding, Tang further suggested that the character jiao 焦 ('Burner'), as used in the context of 三焦 sanjiao ('Triple Burner'), in fact referred to an entity in the body he called youmo 油膜 ('oily membranes'), ${ }^{42}$ and that the Triple Burners hence referred to three physical systems of oily membranes. In contrast to Chinese debates over the shapeless and invisible nature of the Triple Burner, he found Western medical ideas greatly helpful in resolving this controversy once and for all because they depicted in detail the physical configuration of these membranes in their anatomical drawings. The key to resolving this long-standing controversy was therefore, in Tang Zonghai's eyes, not found in Western knowledge per se, but in its visual representations.

It is worth pausing here for a moment. Instead of taking Tang Zonghai's words at face value, let us look more closely at the illustration of the Triple Burner in his book (figure 7). Although he never specified its origin, I suggest that it is a close reproduction of an illustration from the authoritative Gray's Anatomy, which is 'probably the best-known medical textbook in the world. ${ }^{43}$ To be more precise, Tang Zonghai's illustration of the Triple Burner appears to have been copied from a book called Quanti chanwei 全體関微 (Anatomy, Descriptive and Surgical), the first Chinese translation of Gray's Anatomy that had been completed in 1881 by Dauphin W. Osgood. ${ }^{44}$

\footnotetext{
41 Pi $2006 a$, p. 83.

42 Tang 1987 b, p. 26.

43 Richardson 2008, p. 5.

44 The Chinese translation was based on the first American edition of Gray's Anatomy, Descriptive and Surgical, published in 1878. See the preface in Osgood 1881. According to Wong and $\mathrm{Wu}$, the Chinese translation was first published in 1881, and the 800 copies printed were nearly sold out by 1887 (Wong and Wu 1985, p. 455). Tang Zonghai does not provide specific references for the illustrations included in his book but does mention in passing the book titles Quanti tukao 全體圖考 and Quanti chanwei (Tang 1987b, p. 89).
} 
圖 焦 三

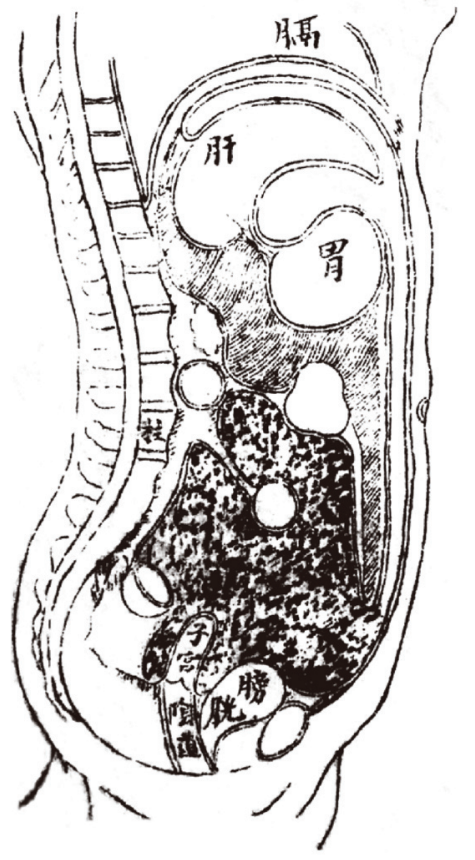

Fig. 7. 'Illustration of the Triple Burner' in Tang Zonghai, Essential Meanings of the Medical Canons (1908), vol. 1, p. 24.

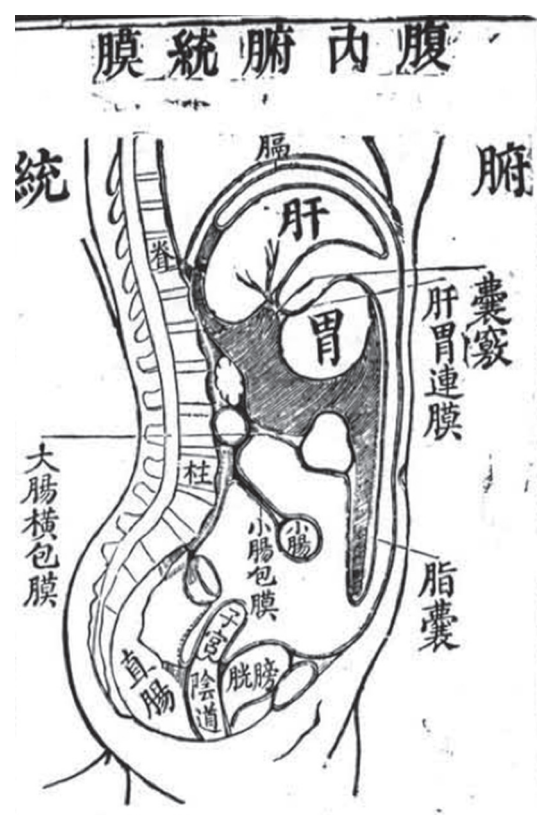

Fig. 8. Illustration of the abdomencovering membranes entitled 'Membranes Connecting the Bowels inside the Abdomen' in Osgood, Anatomy, Descriptive and Surgical, vol. 5, p. 30.

Osgood's Quanti chanwei was the first, though abridged, Chinese translation of Gray's Anatomy. The first complete Chinese translation was John Dudgeon's Quanti Tongkao 全體通考, which was published by a Qing governmental bureau in 1886. The Quanti Tukao Tang Zonghai mentioned is most likely a reference to the two volumes of illustrations contained in the Quanti 


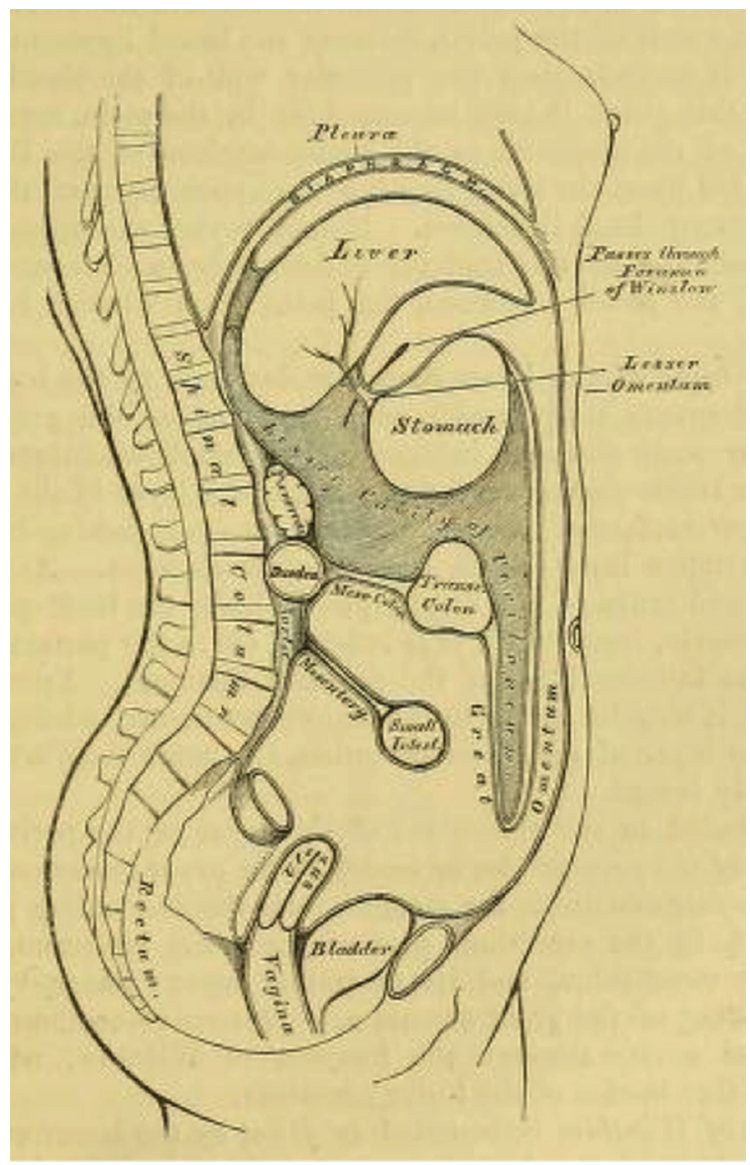

Fig. 9. 'The Reflections of the Peritoneum, as seen in a vertical section of the Abdomen', in Gray's Anatomy (1858), p. 599.

Juxtaposing Tang's illustration of the Triple Burner ${ }^{45}$ (figure 7) with the illustration of the peritoneum in the Anatomy, Descriptive and Surgical ${ }^{46}$ (figure 8),

Tongkao. Based on the Chinese term that Tang Zonghai adopted for the autonomic nervous system, namely zihe naojin 自和腦筋, which is first found in the Quanti Chanwei, it appears that Tang might not have had access to the text of the Quanti Tongkao but instead relied on the Quanti Chanwei. Concerning John Dudgeon's career in China and the publication of the Quanti Tongkao, Gao Xi provides a meticulously documented informative account in Gao 2009, especially pp. 297-312.

45 Tang 1987 b, p. 45.

46 Osgood 1881, p. 223. 
it is obvious that the former is a reproduction of the latter. By way of the Anatomy, Descriptive and Surgical, Tang hence appropriated the Chinese version of the illustration of the peritoneum from Gray's Anatomy (figure 9) to serve as his illustration of the Triple Burner. In his view, the peritoneum in Gray's Anatomy was identical with what he called the 'interconnected net of oily membranes' (lianwang youmo 連網油膜), although it had been translated as 'intra-abdominal bowel-covering membranes' (funei futongmo 腹內 腑統膜) in Osgood's Anatomy, Descriptive and Surgical. Both translations rightly emphasised the term 'membrane' since the peritoneum is a layer of serous membranes that forms the lining of the abdominal cavity. Being connective tissue, no fluids are transmitted through the membranes; however, there is a space between the two layers of membranes that is filled with a small amount of slippery fluids, allowing the two layers to slide freely across each other. This slippery fluid explains why Tang Zonghai coined the term 'oily membrane' (youmo 油膜). Nevertheless, he misunderstood, or misinterpreted, what he had learned from Western medicine and hence suggested that water was transmitted into the bladder via the peritoneum.

If we now take Tang Zonghai's illustration of the Triple Burner (figure 7) and compare it with the illustration of the Triple Burner found in Zhang Jiebin's book (figure 3), we might see how his illustration supported the view represented by Zhang Jiebin that the Triple Burner was a material entity. Although they look very different at first glance, both drawings use a pair of (roughly) parallel lines to depict the Triple Burner as an envelope that covers all major visceral organs. Apparently, Tang Zonghai believed that the detailed lines of the peritoneum in his illustration were simply a more detailed depiction of the envelope that had been sketched out in Zhang Jiebin's illustration of the Triple Burner. No wonder that Tang concluded that 'without Western medicine we would not be able to make these kinds of pathways (daolu 道路) manifest'! $!^{\prime 7}$ At this point of the comparison, however, careful readers will also notice a remarkable difference between the two illustrations: While Tang Zonghai's drawing includes all other major visceral organs, it nevertheless leaves out the only organ presented in Zhang Jiebin's illustration, that is, the kidney. And the kidney, the crucial organ that governs both the Triple Burner and the bladder in Chinese medical theory, shall hence be the subject of the next section.

47 Tang 1987b, p. 127. 


\section{Recognising ureters and re-visualising the kidney}

While the kidney is missing in Tang Zonghai's illustration of the Triple Burner, it is nevertheless the organ that motivated him to equate the Triple Burner with the peritoneum in the first place. As Tang admitted in the Essential Meanings of the Medical Canons, the Western criticism of the Chinese conception of the kidney amounted to an embarrassing crisis for Chinese medicine. Beginning in 1851, the publication date for his Treatise on Physiology (Quanti xinlun 全體新論), Benjamin Hobson criticised Chinese medicine, especially the Canon of Difficulties (Nanjing 難經), for having no knowledge about the function of the kidney as a urinary organ. ${ }^{48}$ From Hobson's point of view, Chinese medicine lacked this understanding because it was missing a specific piece of anatomical knowledge, namely, an awareness of the channel through which liquid waste was carried to the bladder. Taking the Canon of Difficulty again as his target, Hobson refuted its answer that 'the lower end of the small intestines is connected to the entrance of the bladder, and water just moves from one organ into the other. ${ }^{49}$ Instead, Hobson introduced the structure of the ureters, the so-called niguan 溺管 (urinary tubes), a pair of tubes described as propelling urine from the kidneys to the bladder. To demonstrate his point and visually explain this novel structure, Hobson provided three illustrations to show (1) the extension of a ureter out of the kidney (figure 10), (2) the connection between a ureter and the bladder (figure 11), and (3) the connection between the two kidneys and the bladder through the two ureters (See figure 12).

Independent from — and prior to-Hobson's criticism of the Chinese medical view of the kidney, practitioners of Chinese medicine had long been debating the related question of how liquid waste was transported to the bladder. That is precisely the reason why I stated in the previous section ('Depicting the Triple Burner') that Tang Zonghai also believed that Chinese medicine had for centuries wrongly identified the channel through which water was transmitted to the bladder. One conventional view held that food was first digested in the stomach and that then both solid and liquid wastes were transported through the same channel, reaching the large intestines first and then the small intestines. The proponents of this view, however, were then faced with the difficulty to explain how liquid wastes were subsequently transferred from the small intestines into the bladder since no visible channel existed

\footnotetext{
48 Hobson 1851, p. 57.

49 Hobson 1851, p. 58.
} 


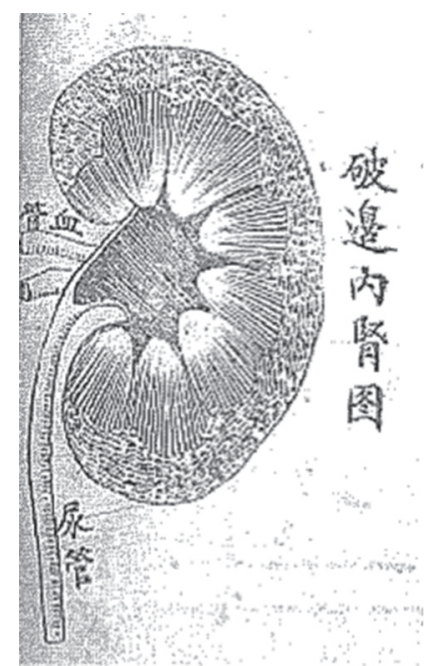

Fig. 10. Illustration of a dissected kidney in Hobson, Treatise on Physiology, p. 48.

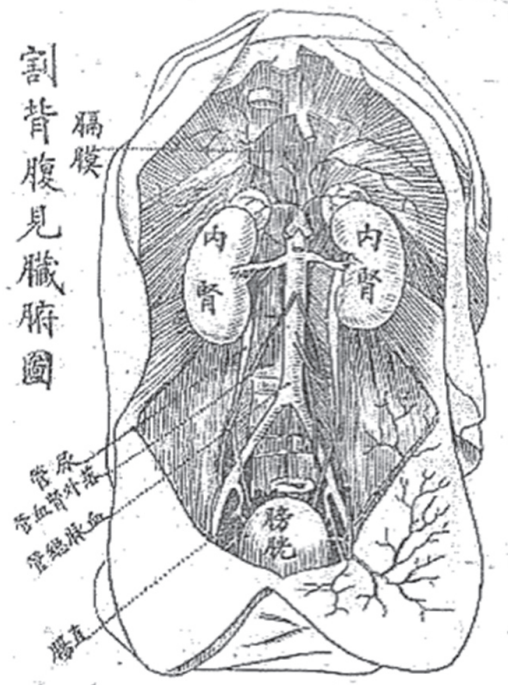

Fig. 12. Illustration of the visceral organs in Hobson, Treatise on Physiology, p. 48.

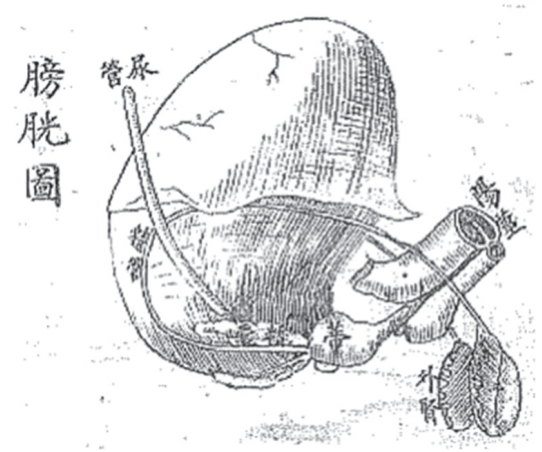

Fig. 11. Illustration of the bladder in Hobson, Treatise on Physiology, p. 48.

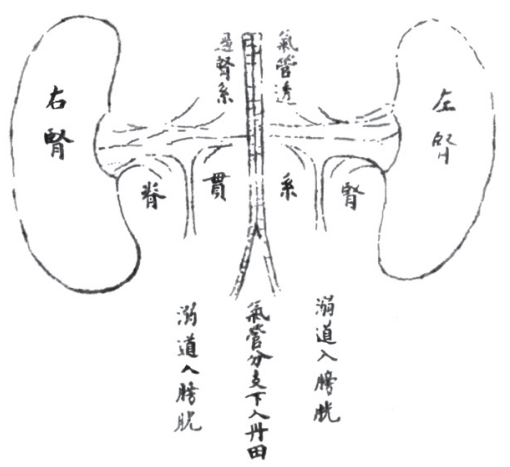

Fig. 13. Illustration of the kidneys in Tang Zonghai, Essential Meanings of the Medical Canons (1908), vol. 1, p. 15. 
that connected these two organs. Decades before Hobson's criticism, Wang Qingren had therefore already declared this theory as absurd. ${ }^{50}$

After explicitly citing the criticisms raised by Hobson and Wang Qingren, ${ }^{51}$ Tang Zonghai admitted that this kind of ridicule and criticism of Chinese medicine was well deserved. But again, he argued that the fault lay not with the medical canons but with the practitioners of his time, who were interpreting the canons incorrectly. A correct understanding of the Inner Canon would show, he hoped, that Chinese medicine had known all along about both the existence of ureters and the urinary function of the kidney. Most interestingly, Tang Zonghai presented his new understanding by means of an illustration of the kidney (figure 13).

As readers can see, this illustration includes a pair of tubes marked with the label 'ureters extending into the bladder' (nidao ru pangguang 溺道入膀胱). It thus appears at first glance that Tang Zonghai indeed rectified the Chinese understanding of the kidney by way of adding to its visual imagery a novel anatomical structure, namely the pair of ureters. But a closer look reveals that his illustration does not depict the ureters as originating from the pair of kidneys, as was clearly the case in both Hobson's illustrations (figures 10 and 12) and in Osgood's translation of Gray's Anatomy. ${ }^{52}$ Instead, the pair of ureters is connected to a bundle of horizontal lines that links the two kidneys to each other and is marked with the caption 'kidney ties that cross the spine' (shenxi guanji 腎系貫㥭). Although Tang Zonghai's illustration of the kidney looks sketchy and preliminary, the difference between his drawing of the ureters and their representation in Hobson's and Osgood's books was by no means a casual mistake. I propose that he deliberately created this visual difference to make a crucial point, namely that the ureters did not originate from the kidneys proper but from the 'kidney ties' (shenxi 腎系). To help his readers comprehend this illustration of the kidneys, he elaborated:

The shape of the [human] kidneys is rather like a bean or a pig's kidney. Between the pair of kidneys, we find an oily membrane crossing the spine, which is the so-called 'kidney ties' followed underneath by an 'interconnected net of membranes'. ${ }^{53}$

By way of assimilating the ureters into this interconnected net of oily membranes,' which Tang had already equated with the peritoneum in Gray's Anatomy and with the Lower Burner, Tang effectively responded to

50 Wang Q.-R. 1985, p. 11.

${ }^{1}$ Tang $1987 b$, p. 43.

52 Osgood 1881, p. 232.

53 Tang 1987b, p. 26. 
Hobson's criticism concerning the urinary function of the kidney. As he put it, 'although the Inner Canon never mentioned the passage of urine through the kidney, ... the kidney surely governs urination because it governs both the bladder and the Triple Burner. ${ }^{34}$

In addition to incorporating the ureters into the system of the Triple Burner, Tang's illustration of the kidney foregrounds the crucial importance of the 'kidney ties'. According to him, all three Burners originated from this 'kidney ties', described as extending downward to form the peritoneum as the Lower Burner, horizontally to form a 'slab of oily membranes' (banyou 板油) in the middle as the Middle Burner, and upward to form the diaphragm as the Upper Burner. ${ }^{55}$ On the basis of this elaboration, he further argued that the 'kidney ties' were actually identical to what was conventionally called 'the gate of life' (mingmen 命門) ${ }^{56}$ since this entity serves as the origin of the Triple Burner in standard Chinese medical theory. ${ }^{57}$ Given the crucial importance of the 'kidney ties', he felt sorry for the Westerners who had known ureters and peritoneum in such detail but had failed to recognise their origin and real function in the context of $q i$-transformation. ${ }^{58} \mathrm{He}$ therefore drew the conclusion that, 'knowing [these structures] is no better than not knowing at all. ${ }^{59}$

At this point, we are faced with an apparent paradox. In appearance, Tang Zonghai radically altered the conception of the kidney as he recognised the novel anatomical structure of the ureters and the kidney's new function in urination. In practice, however, he never reduced the kidney to the sole function of being a part of the urinary system. On the contrary, by endowing the 'gate of life' with a physical structure and creating a visual representation of "kidney ties", he successfully re-established its traditional and seminal status, as part of the kidney system, of governing the qi-transformation of the whole body. Once we take both of these phenomena into account, it looks paradoxical that his visual depiction of the kidney (figure 13) changed so much in comparison with traditional images, while his understanding of the physiological function of the kidney remained virtually identical to the standard theory in Chinese medicine. This apparent paradox leads us to a counterintuitive conclusion: It was precisely because Tang Zonghai managed to alter the visual depiction of certain physical structures (making the ureters part of the peritoneum and asserting the existence of the 'kidney ties') for the purpose

54 Tang $1987 b$, p. 27.

55 Tang $1987 b$, p. 44.

56 For a history of the controversy over the nature of the 'gate of life', see Chang 1998.

57 Tang 1987 b, p. 50.

58 Tang 1987 b, p. 44.

59 Ibid. 
of supporting his argument, that he was able to accommodate a new anatomical structure (ureters) and new knowledge (the urinary function of the kidney) into Chinese medicine without compromising the traditional conception of the kidney. For the sake of highlighting this counter-intuitive phenomenon, the latter part of the subtitle for this section is called 're-visualising the kidney' instead of 're-conceptualising the kidney'.

\section{The reversible transformation between $q i$ and water}

While readers might be surprised by the extent to which Tang Zonghai re-conceptualised the three organs of the bladder, the Triple Burner, and the kidney, these efforts constitute only the first half of his re-conceptualisation of qi-transformation. Up to now, we have discussed only the mechanism and anatomical structures by which water and fire are transported to the bladder and transformed into qi. To create a complete physiology of qi-transformation, however, the reverse process - the transformation of $q i$ back into water-is equally important.

Having established the coupled organs of the bladder and 'cinnabar field' as the origin of $q i$-transformation, Tang Zonghai moved on to deduct what happened both upstream (the arrival of fire and water) and downstream (the generation and transformation of $q i$ ). In terms of the latter, he elaborated:

As the result of kidney yang steaming the water in the bladder, $q i$ rises upward and becomes nourishing fluid. When $q i$ touches things, it transforms back into water; emerging from the skin, it turns into sweat; pouring out from the mouth and nostrils, it turns into mucus and saliva; permeating the inside and outside of the visceral organs, it is generally called nourishing fluid (jinye 津液). ${ }^{60}$

It must be difficult for modern readers to appreciate the novelty and importance of this paragraph, especially the sentence 'When $q i$ touches things, it transforms back into water', because it states such a basic natural phenomenon, taught in grade schools, if not in kindergarten. ${ }^{61}$ Nevertheless, Tang Zonghai considered this basic natural phenomenon to be the very foundation

\footnotetext{
${ }^{60}$ Tang $1987 b$, p. 43.

${ }^{61}$ I would like to thank my colleague Professor Chu Pingyi for discussing with me the significance of this paragraph. This discussion helped me realise that among the major attributes of steam that Tang found most useful for his purpose, one must have been the reversible and mutual transformation between $q i$ and water. Because this trait is such basic knowledge for modern readers, it is difficult for historians as well as for contemporary practitioners of Chinese medicine to recognise how this novel trait was incorporated into the modern conception of $q i$ in Chinese medicine.
} 
of his clinical innovation, putting it in the opening paragraph of his much acclaimed book On Blood Disorders. ${ }^{62}$ Instead of taking it as common knowledge that is known to everyone, he cited this natural phenomenon as 'prominent evidence' (mingzheng 明證) for his allegedly novel argument that $q i$ can be transformed back into water. ${ }^{63}$ If we take his intention to use this phenomenon as 'prominent evidence' for a novel argument seriously, we are rewarded with yet another insight concerning the reasons why he regarded the steam engine as such an apt metaphor for the human body. To put it bluntly, steam was the only kind of $q i$ that could be transformed back into water.

And this characteristic of steam was precisely what made it appear so novel to the Chinese people in the late Qing period. As mentioned in Section Two above, when Hobson coined the term $q i$ 汽 to translate the concept of the steam engine into Chinese, the crucial point that they wanted to emphasise was the fact that steam was a kind of $q i$ that was made out of water. Tang Zonghai was very much aware of the mechanism by which the steam engine transferred steam back into water. In his above-mentioned book, A Generalised Account of Medicine and the Classic of Changes, Tang explained that once steam 'was transferred through a pipe to a cold water tank (lengshuigui 冷水檟) of a steam engine, it was turned back into water. ${ }^{34}$ It is highly possible that he had learned the technical term 'cold water tank' from the illustration of the 'fire-wheel machine' in Hobson's Treatise on Natural Philosophy (figure 1). If you look closely, you find the term at the bottom left-hand corner of the illustration. More importantly, he might have learned from Hobson's text and illustrations that the secret of steam power did not lie solely in 'burning water with fire' but also in turning the generated $q i$ back into water. In short, the steam engine was the perfect vehicle to demonstrate the reversible transformation between $q i$ and water.

Let us now turn to Tang Zonghai's description of how this reversible transformation took place within the human body. Perhaps because most of the processes by which the various fluids were created within the body were invisible, Tang Zonghai focused on the creation of sweat-the visible end-product emerging at the surface of the skin. By way of a microscopic illustration of the sweat glands (banguan 汗管), he explained how sweat emerged from the skin (figure 14). To buttress his point, he noted the observation that people tended to urinate less during the summer even though the intake of water increased substantially during the hot weather. ${ }^{65}$ The reason was that water

62 Tang 2012, p. 4.

${ }^{63}$ Ibid.

${ }^{64}$ Tang 1992, p. 100.

${ }_{65}$ Tang 1987 b, p. 109. 


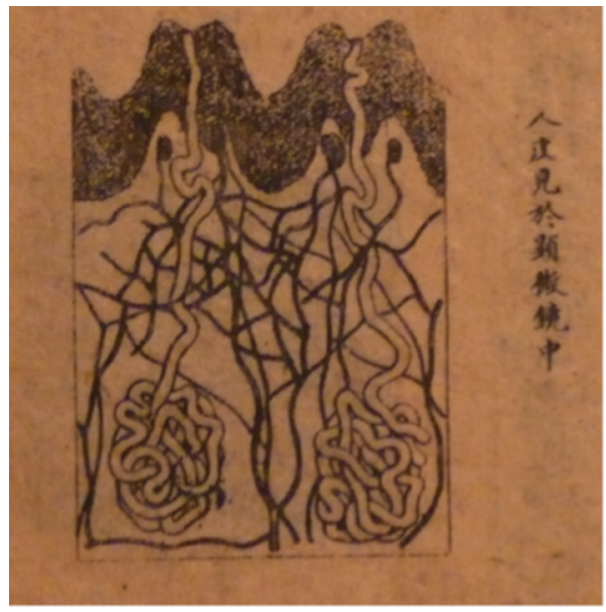

Fig. 14. 'Microscopic view of the human skin' in Tang Zonghai, Essential Meanings of the Medical Canons (1908), vol. 2, p. 12.

was expelled from the body through the skin instead of going down into the bladder. Hence he concluded that 'the origin of sweat is the bladder.' ${ }^{66}$ From this point of view, the puzzling key phrase of the Inner Canon, 'able to exit from here as the result of qi-transformation' (qihua ze neng chu yan), should be interpreted as 'once it has transformed into $q i$, it is then able to exit through the skin as sweat.' ${ }^{67}$ The salient phenomenon of $q i$-transformation was thus, in Tang Zonghai's interpretation, the process of sweat exiting through the skin instead of that of urine being discharged from the bladder.

Combining the two processes of $q i$-transformation, namely the meeting of fire and water and the production of nourishing fluids when ' $q i$ touches things', Tang's conception of qi-transformation basically consisted of the reversible transformation between steam/qi and various kinds of fluids within the body. It is noteworthy here that he directly applied this understanding in his clinical practice, making it the foundation for his acclaimed book

66 Ibid.

${ }^{67}$ My interpretation is supported by his elaboration that 'what the Inner Canon describes as "qihua ze neng chu yan" is meant to suggest that the qi created within the bladder carries the nourishing fluids upward and outward as sweat.' I would like to add that this sweat-centered interpretation is only one of several possible interpretations of this key phrase. For Tang Zonghai, the phrase should be understood in a similar fashion as the discharge of other forms of jinye such as phlegm, saliva, etc. See Tang 2012, p. 15. 
On Blood Disorders. ${ }^{68}$ In the interest of space, I do not elaborate here on the way in which this conception of $q i$ as steam shaped his important contributions to therapeutics; this topic deserves an independent paper. For the purpose of the present paper, it suffices to point out that since water and $q i$ are merely two different states of the same basic substance, Tang therefore asserted in his book a novel therapeutic strategy, namely, 'to treat $q i$ is to treat water and to treat water is to treat $q i .^{69}$

\section{The image of the body as a medium of syncretism}

Up to this point, most scholars have overlooked the important fact that the visual representation of the body, especially of the visceral organs, was the medium that Tang Zonghai adopted to discuss the relationship between Western and Chinese medicine. In the brief preface to his Essential Meanings of the Medical Canons, he listed and commented on five kinds of medical illustrations: (1) traditional Chinese diagrams of the viscera (zangfu tu 臟腑圖); (2) illustrations from Wang Qingren's Correcting the Errors of Medicine; (3) Western anatomical illustrations; (4) traditional diagrams of the acupuncture channels modelled after the so-called 'Bronze Man' figurine created in the Song dynasty; and (5) two illustrations that he had created himself. For him, the central task of integrating Chinese and Western medicine thus consisted of discerning the appropriate ways of reconciling these illustrations by preserving or abandoning them, adding to or subtracting from them, combining them, and ultimately by creating new ones.

While the Song dynasty 'marks a turning point in the graphic representation of the body as in graphic representation in general', ${ }^{70}$ Tang Zonghai nevertheless advocated abandoning all traditional Chinese diagrams of the viscera because 'they were all created after the Song dynasty and therefore mostly did not match the real configurations of the human visceral organs. ${ }^{31}$ Instead, he decided to include in his book both Western illustrations of the visceral organs and those created by Wang Qingren. As he explicitly pointed out in his preface, he arrived at this radical decision because he found that Wang's observations of Chinese bodies overlapped closely with the depictions of visceral organs in Western anatomy.

\footnotetext{
${ }^{68}$ For more information on Tang Zonghai's contributions to the development of Chinese treatments for blood disorders, see Andrews 2010.

${ }_{69}$ Tang 2012, p. 4.

${ }^{70}$ Despeux 2005, p. 47.

71 Tang $1987 b$, p. 1.
} 
Because Tang Zonghai presented his decision in a matter-of-fact fashion, it is easy to miss the crucial role played by Wang Qingren in refuting the once popular view that Chinese and Westerners had fundamentally different bodies. As late as the 1810s, the reputed scholar Yu Zhengxie 俞正熳 (17441840) published a famous article to popularize this view, arguing that it was the precise reason why so many significant discrepancies existed between the human body as depicted in Western anatomical books, which had been introduced to China by the Jesuits in the sixteenth and seventeenth centuries, and the body as described in the Chinese medical canons. ${ }^{72}$ Moreover, this bodily difference in turn served as crucial evidence for Yu's 'moral argument' that Western religions were not suitable for Chinese people. ${ }^{73}$

Tang Zonghai was not the first medical author to refute this view of racial difference on the basis of Wang Qingren's observations. In this aspect, he followed a precedent that had been set in the 1850s. As Yi-Li Wu points out in her recent study of Wang Shixiong 王士雄(1808-68), an important synthesizer of the study of Warm Disorders (wenbingxue 溫病學), a network of scholars and friends centred around him were interested in bodily knowledge and Western learning, exchanging ideas about Western anatomical books and Wang Qingren's newly published book. ${ }^{74}$ Influenced by the Evidential Studies (kaozheng 考證) movement, they were eager to rectify the errors in the classical literature on the basis of new evidence-textual, material, and by direct observation. Perhaps because of this background, when Hu Kun 胡琨, one member of this network, tried to refute Yu Zhengxie's theory of racial difference, he valorised Wang Qingren's observations for the reason that he had investigated the internal organs 'with his own eyes'..$^{75}$ Just like Wang Shixiong and Hu Kun decades before him, Tang Zonghai never observed the internal organs of the Chinese bodies in person but trusted Wang Qingren's firsthand observations. Since he found Wang's observations to be compatible with Western anatomical books, he took many of Wang's criticisms of the Chinese medical body to heart and became eager to learn from the illustrations of Western anatomy.

Tang Zonghai's enthusiasm for Western anatomical illustrations was remarkable but not exceptional. I call it remarkable because previous research has found little evidence that visual illustrations played an important role in the transmission of Western knowledge in the late Qing period. I call it unexceptional, on the other hand, because when Hobson published his New Treatise

72 Zhang 2008, pp. 314-15.

73 Standaert 2000, pp. 792-3, quoted from Wu 2014.

74 Wu 2014.

75 Wang 1999, p. 668. 
on Physiology in 1851, it was very well received in China. Hobson himself felt very satisfied, saying that it has been extensively read and very favourably received, and has proven to be a good foundation for subsequent [work]. ${ }^{76}$ As a testimony to the enthusiastic response by Chinese readers, Wang Shixiong managed to get access to and compare two editions of Hobson's book within a year of their publication. ${ }^{77}$ The book review published in the Chinese Repository went further to articulate the secret of its success:

[This book] is executed in a style so far superior to the Chinese drawings in art as they are in accuracy. The work has probably excited more interest among the reading men of Canton, proud and supercilious as they are as a class in regard to everything done in this line by foreigners, than any work ever before published by foreigners. $^{78}$

As this book review suggests, what interested the Chinese readers most seem to have been the anatomical illustrations, created by means of lithographic printing. In light of such circumstantial evidence, Tang Zonghai's strong interest in anatomical illustrations suggests the rise of a hitherto neglected appreciation for Western visual images, especially in the context of the production and dissemination of scientific knowledge, in the latter half of the nineteenth century.

Although Tang Zonghai openly recognised the validity of some of the major errors that Wang Qingren and Benjamin Hobson had pointed out about Chinese medicine, such as its failure to recognise the existence of the ureters, he never saw these errors as reflecting a fundamental flaw in Chinese medicine. In this sense, he stands in sharp contrast to the Japanese physician Sugita Gempaku 杉田玄白 (1733-1817) who, with the help of a Dutch anatomical textbook, fundamentally repudiated traditional Japanese medical doctrines of the body and thereby inspired the rise of Dutch studies in late eighteenthcentury Japan. More than a century after the publication of Sugita's New Book of Anatomy (Kaitai Shinsho 解體新書), a book 'giving birth to one of the most decisive influences shaping modern Japanese history', ${ }^{79}$ Tang Zonghai reached a very different conclusion from his enthusiasm about Western anatomy:

In spite of the fact that I have adopted the Western diagrams of the viscera, I have not relied on [Western medical] theory alone. In the process of validating them with the Inner Canon, the physical configurations suggested [by these diagrams] were confirmed in every detail. As one endeavours to make sense of the meaning

76 Wong and Wu 1985 , p. 364.

77 Wang 1999, p. 667, quoted in Wu 2010b. Although Wang Shixiong was so interested in Western anatomy, his book did not include any anatomical illustrations.

${ }^{78}$ Choa 1990 , p. 70.

79 Kuriyama 1992, p. 21. 
of the [medical] canons on the basis of these [anatomical] drawings, qi-transformation appears to have become particularly real. ${ }^{80}$

Nothing illuminates this assertion, and by extension, Tang Zonghai's general attitude toward the relationship between Chinese medicine and Western anatomy, more clearly than his illustration of the Triple Burner. Along with the 'Illustration of the five outlets of the stomach', it is the only other illustration that he claimed to have drawn himself. ${ }^{81}$ Given that this drawing is merely a simplified copy of the illustration of the peritoneum from Osgood's Anatomy, Descriptive and Surgical, it seems strange that he claimed to have drawn it himself. This statement becomes even more puzzling when we compare it with the case of the bladder. Just like his illustration of the Triple Burner, the 'illustration of the bladder' (figure 2) is also a direct reproduction of an illustration entitled 'visceral organs in Female Pelvis' from Osgood's book (figure 15), which was in turn a Chinese translation of 'Section of Female Pelvis' from Gray's Anatomy (figure 16). In light of the fact that both of these

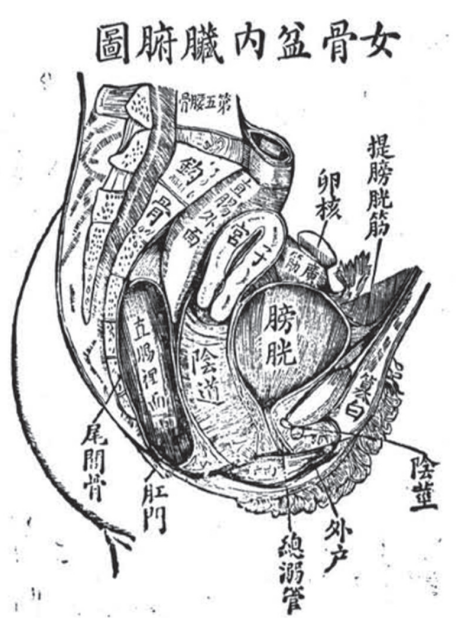

Fig. 15. Illustration of the visceral organs in the female pelvis, in Osgood, Anatomy, Descriptive and Surgical, vol. 5, p. 29.

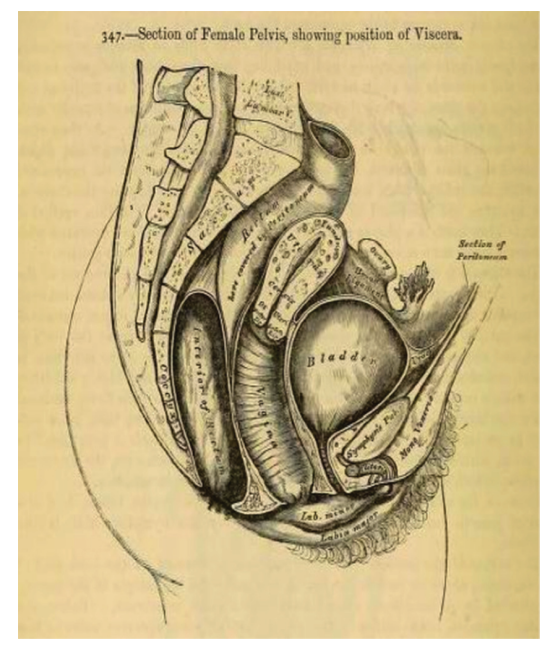

Fig. 16. 'Section of Female Pelvis' in Gray's Anatomy 1st edition (1858), p. 684 .

\footnotetext{
${ }^{80}$ Tang $1987 b$, p. 2.

81 Ibid.
} 
images, that of the Triple Burner and that of the bladder, were copied from Osgood's translation of Gray's Anatomy, one cannot help but wonder in what sense Tang Zonghai felt justified to claim that he had drawn the illustration of the Triple Burner himself but not that of the bladder!

In his eyes, the illustration of the Triple Burner was thus categorically different from the illustration of the bladder, even though both were nothing but woodcut copies of illustrations from Gray's Anatomy. The difference between these two illustrations lies in the fact that the Triple Burner was not a Chinese translation for the Western notion of the peritoneum. In other words, they were not two names for the same physical entity. To say the least, in addition to the peritoneum (which he equated with the Lower Burner), Tang's Triple Burners 'originated from the "kidney ties", extending downward to the uterus and the upper outlet of the bladder to become the Lower Burner, ... and including the diaphragm as the Upper Burner. ${ }^{82}$ In this sense, although his illustration of the Triple Burner was a relatively faithful copy of the illustration of the peritoneum from Osgood's translation, his referents included additional representations of entities that were excluded from his source, namely the illustration of the peritoneum.

Given that Tang Zonghai envisioned all three Burners as originating from the 'kidney ties', it is noteworthy that his illustration of the Triple Burner does not include the pair of kidneys themselves. I speculate that he might have left them out intentionally because of his deep appreciation for the visual representations in Western anatomy. To begin with, the drawing was presented in a cut-away view, a view that was rather novel for his Chinese audience. In sharp contrast to the lack of helpful comments in both Osgood's and Tang's drawings, the translator John Dudgeon (1837-1901) was keenly aware of the need to explain this cut-away view in another, more complete, contemporary Chinese translation of Gray's Anatomy that was published in 1886. To help the viewer comprehend this novel perspective on the human body, Dudgeon provided the following informative subtitle for his illustration of the peritoneum: '[If] the trunk and abdomen were cut in half vertically, the envelope of the peritoneum would present itself like this. ${ }^{83}$ Far from being a 'natural' way of seeing the body, Larissa N. Heinrich has pointed out, the cut-away view 'pretends to go beyond what the eyes can see, claiming to conceive of structures that would be difficult to reach even with the help of the anatomist's knife, and providing a very privileged, if nonexistent, vantage point. ${ }^{84}$

${ }^{82}$ Tang $1987 b$, p. 78.

${ }^{83}$ Dudgeon 1886, vol. 12, p. 17.

${ }^{84}$ Heinrich 2008, p. 130. 
The reason why the cut-away view of the peritoneum simply could not have included the kidneys is clear from this perspective: Because they are located on both sides of the spine, they are invisible in the kind of cross-section of the body depicted by Tang Zonghai, created as if the body had been cut through vertically along the vertebral column from neck to hip with a chain saw. Zhang Jiebin's illustration (figure 3), on the other hand, like most other traditional depictions of the Triple Burner includes the kidney because these images did not strive to represent the internal organs as 'seen' by the eyes. To express this point from another angle, if Tang Zonghai had added the kidneys on to the illustration of the peritoneum from Gray's Anatomy, he would have turned the illustration into a very confusing picture for anybody familiar with the anatomical style of representation. In order to illuminate the triangular relationships between the kidneys, the Triple Burner, and the bladder, as argued earlier, he was thus forced to draw a separate illustration of the kidneys (figure 13) to foreground the 'kidney ties'.

Instead of being a wholesale adoption of either a Western or a traditional Chinese view of the body, Tang Zonghai's drawing of the Triple Burner involved the creation of a new, hybrid, but, to its creator, still highly unsatisfactory illustration. Since it demonstrated the ignorance of Western anatomy regarding the 'function, proper name, and origin' of the Triple Burner, ${ }^{85}$ he felt the strong need to complement it with a separate illustration for the kidney. Viewed in conjunction, these two illustrations reveal two opposite implications for the way in which their creator conceived the relationship between Chinese medicine and Western anatomy. On the one hand, since Western anatomical illustrations offered visual evidence for the Triple Burner, which had long been a controversial and allegedly invisible, even immaterial, entity in Chinese medicine, this case strongly suggested that anatomical illustrations might help to visualise other material entities involved in the process of qi-transformation. The case of the Triple Burner provided the most vivid evidence for Tang Zonghai's assertion that 'as one endeavours to make sense of the meanings of the [medical] canons on the basis of these [anatomical] drawings, $q i$-transformation appears to have become particularly real. ${ }^{986}$

By way of depicting the 'kidney ties', on the other hand, the illustration of the kidney provided a concrete example of what Western anatomy could learn from Chinese medicine. Here it is crucial to point out that Tang's understanding of these 'kidney ties' was light-years removed from the 'invisible and immaterial realm of $q i$-transformation'. Quite to the contrary, it was a

${ }^{85}$ Tang $1987 b$, p. 50.

${ }^{86}$ Osgood 1881, p. 2. 
concrete anatomical structure that was physically connected to the ureters and therefore depicted clearly in the illustration by Tang. This illustration provides strong evidence that the practitioners of Chinese medicine in the late nineteenth century, at a time when they were actively incorporating Western anatomy into traditional medical doctrines, did not regard the visual representation of the human body as a monopoly of Western medicine. ${ }^{87}$ When Tang Zonghai used the visual representation of the kidney to expose the ignorance of Western anatomy, he formally started the historic and problematic process of visualising the body in terms of Western anatomy.

\section{Conclusion}

This article began with a puzzle: If $q$ i-transformation as Tang Zonghai formulated was the incommensurable opposite of modern science (as understood by the critics and reformers of Chinese medicine in the 1930s), how could it possibly serve as a tool for converging Chinese medicine and Western anatomy in the late nineteenth century? In the process of resolving this puzzle, this article has made three related discoveries. First, Tang Zonghai drew on the newlyinvented model of the steam engine and the related concept of steam to create a new understanding of $q$ i-transformation in the human body. Second, this new understanding of $q i$ enabled him to reform Chinese medicine by incorporating the new knowledge and visual illustrations of Western anatomy, most notably the illustration of the peritoneum from Gray's Anatomy and the existence of the ureters. And third, in the dual process of developing this new understanding of $q$ i-transformation and incorporating Western anatomy into Chinese medical doctrines, he radically re-conceptualised and re-visualised the body of Chinese medicine, especially the three interrelated organs of the bladder, the Triple Burner, and the kidney. Instead of creating an invisible and immaterial world of $q i$-transformation in opposition to the materialism of Western anatomy, Tang Zonghai made his conception of qi-transformation instrumental for the incorporation of Western anatomy into Chinese medical doctrines. With the help of this new understanding of $q i$ as steam, he systematically responded to the criticisms raised by Benjamin Hobson and Wang Qingren, formally starting the difficult and problematic process of (re)-visualising the Chinese medical body in terms of Western anatomy. Having summarised the radical innovations that originated from Tang Zonghai's new conception of $q$-transformation, I would like to re-examine the concept

87 Concerning the role of images in Chinese medicine, see Wang and Lo 2007. 
of $q i$ as steam in this conclusion since it constitutes his most long-lasting but least-recognised legacy. The key question here is this: Why and how did his understanding of $q i$ as steam pave the way for this radical re-conceptualisation and visualisation of the Chinese medical body? Or in other words, what was so special about this new understanding of $q i$ as steam?

The answer to this question brings us back to the title of this article, 'Qi-Transformation and the Steam Engine'. This title is somewhat misleading, if taken literally, because Tang Zonghai mentioned the term 'steam engine' (qiji 汽機) only once in his entire book Essential Meanings of the Medical Canons. ${ }^{88} \mathrm{My}$ title intentionally highlights this term nevertheless, because what he characterised as the 'Western method' of 'using fire to boil water and collecting steam' was by no means a reference to the daily phenomenon of boiling water. Instead, what he had in mind was precisely the notion of steam as a new source of power, whose production was inseparable from the machinery of the steam engine, such as the use of airtight containers and the cooling device of the 'cold-water tank'. In this sense, the concept of steam does not refer to a natural phenomenon but rather to a 'created phenomenon', in the sense suggested by the philosopher of science Ian Hacking. ${ }^{89}$

In other words, what motivated Tang Zonghai to fundamentally reinterpret the Inner Canon was his fascination with a brand-new source of power that had opened the door to the historic epoch of the Industrial Revolution. During the later half of the nineteenth century, he was by no means alone in perceiving this parallel between the human body and the steam engine. As Anson Rabinbach has beautifully analysed in The Human Motor: Energy, Fatigue, and the Origins of Modernity, thermodynamics gave rise to a globally-circulated new image of the human body as a motor. ${ }^{90}$ Because the first law of thermodynamics posited energy as the invisible source of all matter and motion, it became possible to view nature, industrial machines, and human bodies as instances of a universal process of energy and mechanical work. In light of this global trend of viewing the human body as an energy machine, Tang Zonghai's conception of $q i$ as steam reflected his appreciation of a new concept, for which he did not have an appropriate Chinese word at that time, namely 'energy' .

The concept of energy served Tang Zonghai's objective of converging the two styles of medicine quite well. First of all, as the philosopher of science Gaston Bachelard once described, because nineteenth-century scientific materialism was embodied in the primacy of energy, it was a peculiar kind of 'dematerialised materialism'. Unlike traditional materialism, which had

\footnotetext{
88 Tang 1908, vol. 2, p. 38.

89 Hacking 1983, pp. 220-33.

90 Rabinbach 1990, especially pp. 45-68.
} 
emphasised tangible and visible entities, the materiality of energy is nowhere to be seen except in its manifest effects. Moreover, since the first law of thermodynamics (conservation of energy) unites all forms of work, the concept of energy completely upset the traditional boundary between the animate and the inanimate. Although Tang Zonghai never explicitly referred to the concept of energy, it was no accident that the concept of $q i$ as steam effectively bridged the gulf between Chinese medicine and the inanimate, visible configurations of Western anatomy. In this sense, I argue that his pioneering work laid the foundation for the subsequent understanding of $q i$ as related to energy - with cautious qualification to be sure-in contemporary thinking of Chinese medicine. Ever since then, the concept of energy has served as a 'necessary but inappropriate' mediator for our understanding of $q i$.

Reversely, however, it is noteworthy that Tang Zonghai's pioneering conception of $q i$ could not be reduced to the concept of energy. Nathan Sivin once pointed out in the introduction to his important English translation of the Revised Outline of Chinese Medicine (Xinbian Zhongyixue Gaiyao 新 編中醫學概要): 'I did not translate $c h$ ' $[q i]$, but sometimes I describe certain aspects of it as "vitalities" or "energies"... Neither "vitality", "energy", nor "pneuma" . . can be used consistently as English equivalent of $c h$ ' $i$ [qi]. ${ }^{91}$ To summarise Sivin's position, 'Ch'i [qi] provides a language for thinking about the stuff involved in change, as well as the energies that make change possible. ${ }^{.92}$ In comparison to the understanding of $q i$ as energy, Tang Zonghai's conception of $q i$ as steam better captures the traditional meanings of $q i$ that involve at the same time the connotations of 'stuff' and 'energies'.

Finally, the concept of steam appealed to Tang Zonghai not just because it was linked to a revolutionary new source of power. It was also attractive to him because the machinery of the steam engine foregrounded the reversible transformation between $q i$ and water. Likewise, his physiology of $q i$-transformation involved both the creation of $q i$ when fire comes across water and the production of nourishing fluids when ' $q i$ touches things'. By way of emphasising the reversible transformative relationship between $q i$ and water, Tang Zonghai fundamentally transformed the traditional hierarchical relationship between $q i$ and water, which was just one among the five phases or 'elements' (wuxing 五行) correlated in the theory of systematic correspondences. As Sivin elegantly summarised, because each of the five phases 'describes a complementary part of a process or configuration in which $c h$ ' $i$ [qi] is the agent of both change and stable identity', the five phases serve as a set of labels for

\footnotetext{
91 Sivin 1987, p. 47.

92 Sivin 1987, p. 53.
} 
classifying $q i .^{93}$ Because this newly invented reversible transformative relationship between $q i$ and water made the relationship between the 'label' and 'what is labelled' interchangeable, this new formulation amounted to a revolution in the theoretical framework of Chinese medicine.

Perhaps it is precisely because Tang Zonghai was keenly aware of the revolutionary potential of his new formulation that he placed this formulation in the opening paragraph of his book On Blood Disorder. 'On what basis do I suggest that water is something that is transformed from $q i$ ? When $q i$ touches things, it transforms back to water. This is the prominent evidence for it. ${ }^{94}$ After citing this observation of a natural phenomenon and taking it as his point of departure, however, Tang went on to differentiate two kinds of water, the visible substance of water (youxing zhi shuizhi 有形之水質) and water as invisible yin (wuxing zhi shuiying 無形之水陰). ${ }^{95} \mathrm{He}$ created this distinction in order to protect the notion of water as one of the five phases from the disruptive formulation that he himself had introduced into the cosmology of Chinese medicine. While the reversible transformation between water and $q i$ was thus a radical contribution in the eyes of Tang Zonghai and his contemporaries, it is easy for modern readers to miss its importance and novelty, and to merely treat it as a restatement of a natural phenomenon known to everyone at all times. As a result, the contemporary community of Chinese medicine considers $q i$-transformation as a fundamental characteristic of Chinese medicine without realising that it was a recent and revolutionary formulation modelled upon the machinery of the steam engine. In light of the case discussed in this article, one challenge for medical historians is to make visible this kind of 'invisible revolution' in the modern history of Chinese medicine.

\section{Acknowledgements}

Earlier versions of this paper were presented at the Workshop on "The (After) Life of Traditional Knowledge" (Westminster University, August 2010), the 4th International Conference of the European Society for the History of Science (Barcelona, November 2010), "Visual Culture in Medicine" (Academia Sinica, December 2010), "From Qing to China: Re-thinking the Interplay of Tradition and Modernity, 1860-1949" (Tel Aviv University, May 2012), and "Images: Scientific and Artistic" (Korea Institute for Advanced Study, January

\footnotetext{
93 Sivin 1987, p. 76.

94 Tang 2012, p. 5.

95 Ibid.
} 
2013). I would like to thank the organizers Howard Chiang, Carla Nappi, Volker Scheid, Karin Chemla, Pingyi Chu, Asaf Goldschmidt, Ori Sela, and Sungook Hong for their invitations, and conference participants, especially Elisabeth Hsu, T. J. Hinrichs, Yi-Li Wu, and Guoli Pi for their questions and comments.

Whenever I benefited from helpful comments in the process of writing this article, I have documented the specifics in the footnotes. In addition, I would like to thank my colleagues Che-chia Chang and Miaw-fen Lu. They carefully read through the whole paper and provided critical but helpful comments in their role as discussants in a seminar at the Institute of Modern History, Academia Sinica. Ping-yi Chu, Yu-qun Liao and Jongtae Lim engaged me in lengthy discussions and offered insightful suggestions. I also want to express my gratitude for suggestions from the following practitioners of Chinese medicine: Hen-hong Chang, Yue-feng Li, Ching-mao Chang, and especially Guangwei Chen who shared with me a beautiful late Qing copy of the Essential Meaning of the Medical Canons. As always, I feel very grateful toward Dr. Sabine Wilms for her superb editorial work. Finally, I want to thank the two anonymous reviewers of Asian Medicine and its senior co-editor, Marta Hanson, for their helpful comments and suggestions.

\section{References}

Andrews, B. J. 1991, 'Wang Qingren and the History of Chinese Anatomy', Journal of Chinese Medicine, 35: 30-6.

—. 2007, 'Introduction', in Wang Qingren, Yilin gaicuo, translated with commentary by Yuhsin Chung, Herman Oving, and Simon Becker, Boulder, CO: Blue Poppy Press, v-xiv.

— 2010, 'Blood in the History of Modern Chinese Medicine', paper presented in a workshop on '(After)Life of Traditional Knowledge: The cultural politics and historical epistemology of East Asian medicine’, 20-21 August 2010, Westminster University, London.

Balme, H. 1921, China and Modern Medicine: A study in medical missionary development, London: United Council for Missionary Education.

Bray, F. 2007, 'Introduction: The powers of tu', in F. Bray, V. Dorofeeva-Lichtmann, and G. Métailié (eds), Graphics and Text in the Production of Technical Knowledge in China: The warp and the weft, Leiden and Boston: Brill, 1-78.

Cardwell, D. S. L. 1989 [1971], From Watt to Clausius: The rise of thermodynamics in the early industrial age, Ames: Iowa State University Press.

Chang, C.-F. 1998, 'Shenghua zhi yuan yu liming zhi men: Jinyuanming yixue zhong de mingmen shitan' [The Gate of Life: the conceptions of Mingmen in Traditional Chinese Medicine in the Chin, Yuan, Ming periods], Xinshixue [New Historiography], 9(3): 1-48.

Choa, G. H. 1990, 'Heal the Sick' Was Their Motto: The protestant medical missionaries in China, Hong Kong: The Chinese University Press.

Deng, T. (ed.) 1999, Zhongyi Jindaishi [Modern history of Chinese medicine], Guangdong: Guangdong Gaodeng Jiaoyu Chubanshe. 
Despeux, C. 2005, 'Visual Representations of the Body in Chinese Medical and Daoist Texts from the Song to the Qing Period', Asian Medicine - Tradition and Modernity, 1 (1): 10-52.

Dudgeon, J. 1886, Quanti Tongkao [Comprehensive examination of human anatomy] vol. 12, Beijing: Tongwen Guan.

Gao, X. 2009, Dezhen Zhuan: Yige yingguo chuanjiashi yu wan Qing yixue jindaihua [A biography of John Dudgeon: A British missionary and the medical modernization in late Qing China], Shanghai: Fudan Daxue Chubanshe.

Goldschmidt, A. 2005, 'The Song Discontinuity: Rapid Innovation in Northern Song Dynasty Medicine', Asian Medicine - Tradition and Modernity 1 (1): 53-90.

Hacking, I. 1983, Representing and Intervening, Cambridge: Cambridge University Press.

Heinrich, L. N. 2008, The Afterlife of Images: Translating the Pathological Body between China and the West, Durham and London: Duke University Press.

Hobson, B. (He Xin) 1851, Quanti xinlun [Treatise on Physiology], Guangzhou: Huiai Yiguan. Digital version can be found in National Library of Australia.

- 1855, Bowu xinbian [Treatise of natural philosophy], Shanghai: Mohai shuguan.

—. 1858, A Medical Vocabulary in English and Chinese, Shanghai: Shanghai Mission Press.

Kuriyama, S, 1992, 'Between Mind and Eye: Japanese anatomy in the eighteenth century', in C. Leslie and A. Young (eds), Paths to Asian Medical Knowledge, Berkeley: University of California Press, 21-43.

Lackner, M., I. Amelung, and J. Kurtz, 2001, New Terms for New Ideas: Western Knowledge and Lexical Change in Late Imperial China, Leiden and Boston: Brill.

Lei, S. H. 1999, 'When Chinese Medicine Encountered the State', Ph.D. Dissertation, The University of Chicago.

Osgood, D. W. 1881, Quanti Chanwei [Anatomy, descriptive and surgical], vol. 4, Fuzhou: Meihua Shuguan.

Palmer, D. A. 2007, Qigong Fever: Body, science, and utopia in China, New York: Columbia University Press.

Pi, G.-L. 2006a, 'Tuxiang Xingzhi Yu Zangfu Zhishi-Tang Zonghai Sanjiaolun de qishi [Imagery, materiality and information on the viscera: Lessons from Tang Zonghai's view on the Triple Burner]', Gujin Lunheng [Disquisitions on the Past \& Present], 15: 71-98.

—. 2006b, Yitong Zhongxi: Tang Zonghai yu jiandai zhongyi weiji [Communication between Chinese and Western medicine: Tang Zonghai and the crisis of Chinese medicine in modern times], Taipei: Dongda Tushu Gongsi.

Porkert, M. and C. Ullmann 1982, Chinese Medicine, New York: Henry Holt and Company.

Rabinbach, A. 1990, The Human Motor: Energy, fatigue, and the origins of modernity, Berkeley: University of California Press.

Richardson, R. 2008, The Making of Mr Gray's Anatomy: Bodies, Books, Fortune, Fame, Oxford: Oxford University Press.

Sanetô, K. 1982, Zhongguoren Liuxue Riben Shi [A History of Chinese Overseas Studies in Japan], Hong Kong: The Chinese University Press.

Sivin, N. 1987, Traditional Medicine in Contemporary China, Ann Arbor: University of Michigan Press.

Standaert, N. 2000, Handbook of Christianity in China, 635-1800, Leiden: Brill.

Tang, Z.-H. 1908. [1892], Zhongxi Huitong Yi Jing Jing Yi [Essential meanings of the medical canons [approached] through the convergence and assimilation of Chinese and Western medicine], Shanghai: Qianqingtang Shuju.

—. 1987a [1880], Bencao Wenda [Questions and answers on materia medica], Taipei: Lixing Shuju.

-1987b [1892], Zhongxi Huitong Yi Jing Jing Yi [Essential Meanings of the medical canons [approached] through the convergence and assimilation of Chinese and Western medicine], Taipei: Lixing Shuju. 
1992 [1910] Yiyi tongshuo [A generalised account of medicine and the Classic of Changes], Chengdu: Bashushudian.

- 2012 [1893], Xue Zheng Lun [On blood disorders], Beijing: Xueyuan Chubanshe.

Wang, B. 1986 [762], Huangdi Neijing Suwen [Inner canon of the yellow emperor: Basic questions], Taipei: Shijie Shuju.

Wang, D.-H. 1995, 'Lun Yilin Gaicuo de jiepoxue jian lun jiepoxue zai zhongxi yixue chuantong zhong de diwei' [Wang Qingren on human anatomy]', Xinshixue [New Historiography] 6(1): 95-115.

Wang, H.-J. and Zhang J.-Y. 2010, 'Pangguang de jiben shengli gongneng: Chucang jinye' [On the basic physiological function of the bladder: Conserving nourishing fluids], Liaoning Zhongyiyao daxue xuebao (Journal of Liaoning University of TCM), 12 (2): 63-4.

Wang, H-C. 2010, 'Discovering Steam Power in China, 1840s-1860s', Technology and Culture, 51:31-54.

Wang, M.-M. and Li L. 1999, Tang Rongchuan yixue quan shu [The complete collection of medical works by Tang Rongchuan], Beijing: Zhongguo Zhongyiyao Chubanshe.

Wang, Q.-R. 1995 [1830], Yilin gaicuo [Correcting the Errors of Medicine], Taipei: Lixing Shuju.

Wang, S.-X. 1999 [1855], Chongqingtang Suibi [Jottings from the Hall of Repeated Celebrations], reprinted in Wang Mengying Yixue Quanshu [The Complete Collections of Wang Mengying's Medical Books], Beijing: Zhongguo Zhongyiyao Chubanshe.

Wang, S.-M. and V. Lo. 2007, Xingxiang Zhongyi [Imagining Chinese Medicine], Beijing: Renmin Weisheng Chubanshe.

Wang, T. 1987, Wang Tao Riji [Diary of Wang Tao], Beijing: Zhonghua Shuju.

Wong, K. C. and L. Wu 1985 [1932], History of Chinese Medicine, Taipei: Southern Materials Center, INC.

Wu, Y.-L. 2010a, Reproducing Women: Medicine, metaphors, and childbirth in late Imperial China, Berkeley: University of California Press.

- 2014, 'Bodily Knowledge and Western Learning in Late Imperial China: The case of Wang Shixiong (1808-68)', in Howard Hsueh-Hao Chiang, ed., Historical Epistemology and the Making of Modern Chinese Medicine, Manchester: University of Manchester Press, projected 2014.

Xie, G. 1935, Zhongguo Yixue Yuanliulun (The historical development of Chinese medicine), Shanghai: Shanghai Zhongyi Chubanshe.

Xu, S. 1876, 'Qiji Mingming Shuo' [On the name 'steam machine'], Gezhi Huibian [The Chinese scientific magazine], 1 (6): 6-8.

Zhang, Q. 2008, 'Hybridizing Scholastic Psychology with Chinese Medicine: A SeventeenthCentury Chinese Catholic's Conception of Xin (Mind and Heart)', Early Science and Medicine 13: 313-60. 